IIIIIIIIIIIIIIII OF STAND \& TECH

983944

\title{
$83-2649(R)$
}

\section{Annual Report Office of Standard Reference Materials}

U.S. DEPARTMENT OF COMMERCE National Bureau of Standards

Washington, DC 20234

October 1982

Final

Issued February 1983

Prepared for

1 S. DEPARTMENT OF COMMERCE

$-Q C$

100

.456

83-2649

1983 tional Bureau of Standards shington, DC 20234 

NBSIR 83-2649

\section{ANNUAL REPORT \\ OFFICE OF STANDARD REFERENCE \\ MATERIALS}

G. A. Uriano and S. D. Rasberry, Editors

U.S. DEPARTMENT OF COMMERCE

National Bureau of Standards

Washington, DC 20234

October 1982

Final

Issued February 1983

Prepared for

U.S. DEPARTMENT OF COMMERCE

National Bureau of Standards

Washington, DC 20234

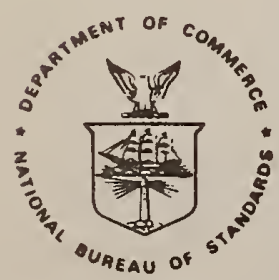

U.S. DEPARTMENT OF COMMERCE, Malcolm Baidrige, Secretary NATIONAL BUREAU OF STANDARDS, Ernest Ambler, Director 

TABLE OF CONTENTS

$\underline{\text { Page }}$

1. INTRODUCTION

1.1 Special Format for This Report . . . . . . 1

2. UPDATE 1982

(ANAL, CHEM, Pages)

Inventory Status . . . . . . . . . $1226 \mathrm{~A}$

Technology of Certification. . . . . . . 1228 A

International Progress . . . . . . . . . $1235 \mathrm{~A}$

Recently Introduced SRM's (SRM Production). - $1236 \mathrm{~A}$

Metals, Ores, and Minerals...... $1236 \mathrm{~A}$

Energy Related and Environmental. . . $1236 \mathrm{~A}$

Biological/Botanical Matrix...... $1241 \mathrm{~A}$

Clinical............. . . 1241 A

Thermometry, Spectrophotometry,

and Fluorescence. . . . . . . . $1242 \mathrm{~A}$

Wear Metals in Lubricating 0i1..... $1242 \mathrm{~A}$

Microanalysis.......... . . 1242 A

Radioactivity and Nuclear..... . . 1242 A

Trends and Future Emphasis......... 1244 A

References.............. 1244 A

3. TECHNICAL ACTIVITIES

3.1 Summary of New and Renewal SRM's ....... 2

3.2 FY82 SRM Sales Report............. 2

3.3 Data Base Management System. . . . . . . . 5

3.4 Highlights of Research Projects....... . 5

. 1 Radioactivity Research..... . . . . 5

.2 Surface-analysis Methods....... . 6

. 3 Chemical Thermodynamics Measurements. . 9

.4 Measurement of $\mathrm{pH}$. . . . . . . . . . 11

.5 Isotope Dilution Mass Spectrometry of Gases............. 13

.6 Gases in Metals . . . . . . . . 14

.7 Increased Sensitivity in NAA by Background Reduction. . . . . . . 15

.8 High Sensitivity Measurements . . . . . . 17

.9 Analysis of SRM 1649, Urban Dust/Organics, for the Determination of Polycyclic Aromatic Compounds... . 19

. 10 Methods for the Determination of Vitamins in Milk........ 20 
.11 Development of an Isotope Dilution/ Mass Spectrometric Definitive Method for the Determination of Serum Urea. . . 28

.12 Improved Instrumentation for Organic Isotope Dilution/Mass Spectrometry Measurements... . . . . . . . 32

.13 Surface Reactions of Gas Mixtures: . . 34

.14 XRD Crystallite Size......... 39

.15 Chemical Speciation/Biodeterioration

. 16 Research on Dye Penetrant,

Microhardness and Thickness SRM's... . 43

.17 Glass Standard Reference Materials. . . 44

. 18 Catalyst Package for Lubricant

19 Oxidation Tests . . . . . . . 4 45

Self-Calibrating Gel Permeation
Chromatography. . . . . . 46

.20 Metallurgical Research.........448

.21 Computer Magnetic Media . . . . . . . 50

.22 Absolute Layer Thickness Measurements

for Semiconductor Materials ..... . 51

4. OSRM STAFF PUBLICATIONS, INFORMATION TRANSFER AND COMMITTEE ACTIVITIES

4.1 Publications, Journal Articles, and Written

4.2 Technical Lectures/Talks Given by OSRM

Personnel.............. . 53

4.3 Standards Committee and other Standards

4.4 NBS Special Pubiication 260 series: : :

4.5 FY82 Technical Exhibits with Staffed 


\subsection{Special Format for This Report}

The FY 1982 annual report for the office of Standard Reference Materials is notably different in appearance from previous editions. This year the office was honored by the Analytical Chemistry journal in having the essential portions of the annual report published as the cover story for 0ctober 1982. That lead story is reproduced, in section II as the basis of this report. Additional details are incorporated in subsequent sections.

\section{${ }^{\star}$ Disclaimer:}

Certain commercial equipment, instruments, or materials are identified in this report in order to adequately specify the exerimental procedure. Such identification does not imply recommendation or endorsement by the National Bureau of Standards, nor does it imply that the materials or equipment identified are necessarily the best available for the purpose. 


\section{Robert Alvarez \\ Stanley D. Rasberry \\ George A. Uriano}

Office of Standard Reference Materials

National Bureau of Standards

Washington, D.C. 20234

\section{MBS Standard Reference Materials:}

Update 1982

In 1966, the National Bureau of Standards reported in ANALYTICAL CHEMISTRY (1) the rejuvenation of its Standard Reference Materials program. Ten years later an update, noting considerable progress, was reported in ANALYTICAL CHEMISTRY (2). Now, after only six years, so much has changed in this 76-year old program that readers of the JOURNAL may be interested in a status report. It is the purpose of this REPORT to update the scope and results of this program to 1982 and to provide a glimpse of the future.

The National Bureau of Standards (NBS) provides several types of services to scientific, technical, and commercial interests. Among these are calibration of measuring devices, Standard Reference Data, and Standard Reference Materials (SRMs). In analytical chemistry laboratories, the best known of these services is probably SRMs, since a majority of those issued are certified for chemical composition primarily through the efforts of the NBS Center for Analytical Chemistry.

In general, SRMs are well characterized homogeneous materials or simple artifacts with specific chemical or physical properties certified by the NBS. For 76 years they have been sold by NBS-recently at the rate of about 40000 per year-to help ensure accuracy of measurement. More than $80 \%$ of the SRMs distributed are used in industrial measurement applications, such as maintaining quality control in the production of materials and goods. Of the 100 largest industrial companies in the U.S., 83 purchased SRMs in a recent fiscal year (3).
About one-quarter of all SRMs are used outside the U.S. Both domestically and worldwide, SRMs are used in the development of test methods of proven accuracy and to ensure the long-term reliability and integrity of the measurement process. The development of new SRMs is frequently a difficult and expensive proposition. While the purchasers of the materials defray production costs, NBS has contributed considerable technological support and the institutional stability to guarantee continuity of service. Some SRMs (or their renewal counterparts) have been available for more than 70 years.

Earlier papers $(1,2)$ related the development of SRMs under the leadership of W. Wayne Meinke through 1966 and under J. Paul Cali through 1976. This REPORT will provide an update on the inventory status to 1982. Following brief reviews on technology of certification and progress in international cooperation, most of this REPORT will describe recently issued SRMs that are of particular interest to analytical chemists.

\section{Inventory Status}

Table I provides an update on the SRM inventory from the previous paper (2) to the present. Immediately apparent is a reduction of 97 SRMs since the last REPORT. The current stock of SRM types stands at 870down from a record high of 1063 in July 1980 . The reduction, by and large, represents "housekeeping" adjustments in the inventory. In such cases, technological changes have rendered obsolete those SRMs that were discontinued. In other cases, losses in a given technical capability at NBS have made it impossible to renew cer-
Table I. SRM Inventory-1966, 1976, and 1982

\begin{tabular}{|c|c|c|c|}
\hline Calogory & $\frac{\text { SRMs }}{T 1966}$ & $\frac{\ln \ln v}{1976}$ & ontory \\
\hline 1. Metals, ferrous & 167 & 219 & 173 \\
\hline 2. Metals, nonferrous & 96 & 98 & 127 \\
\hline 3. Ores, cements, ceramics & 28 & 41 & 50 \\
\hline 4. Organics, metallo-organics & 32 & 34 & 22 \\
\hline 5. High-purity metals & 0 & 8 & 10 \\
\hline 6. Electron microprobe & 0 & 6 & \\
\hline $\begin{array}{l}\text { 7. Primary and secondary } \\
\text { chemlcals }\end{array}$ & 10 & 12 & \\
\hline 8. Microchemlcals & 5 & 10 & 8 \\
\hline 9. Cllnical & 0 & 21 & 27 \\
\hline 10. Biological and botanlcal & 0 & 5 & 9 \\
\hline 11. Environmental-gases & 3 & 24 & 70 \\
\hline $\begin{array}{l}\text { 12. Environmental-llquids } \\
\text { and solids }\end{array}$ & 0 & 14 & 28 \\
\hline 13. Forensic & 0 & 3 & 2 \\
\hline 14. Fertilizers & 0 & 3 & 0 \\
\hline 15. Glasses & 11 & 30 & 32 \\
\hline 16. Nuclear and Isotoplc & 27 & 46 & 38 \\
\hline 17. $\mathrm{pH}, \mathrm{pD}$, ion-selective & 6 & 17 & 17 \\
\hline 18. Mechanical propertles & 37 & 89 & 40 \\
\hline 19. Heat properties & 11 & 64 & 40 \\
\hline 20. Magnetic properties & 0 & 9 & 16 \\
\hline 21. Optical properties & 28 & 31 & 22 \\
\hline 22. Radioactivity properties & 37 & 86 & 58 \\
\hline 23. Miscellaneous physical & 5 & 35 & 14 \\
\hline
\end{tabular}
properties (incl.) metallurgical, Mössbauer, X-ray

24. Engineering propertiesrubber and polymers

25. Engineering propertiescolor

26. Engineering propertiesother

27. Research materials

28. General materials Tolals 


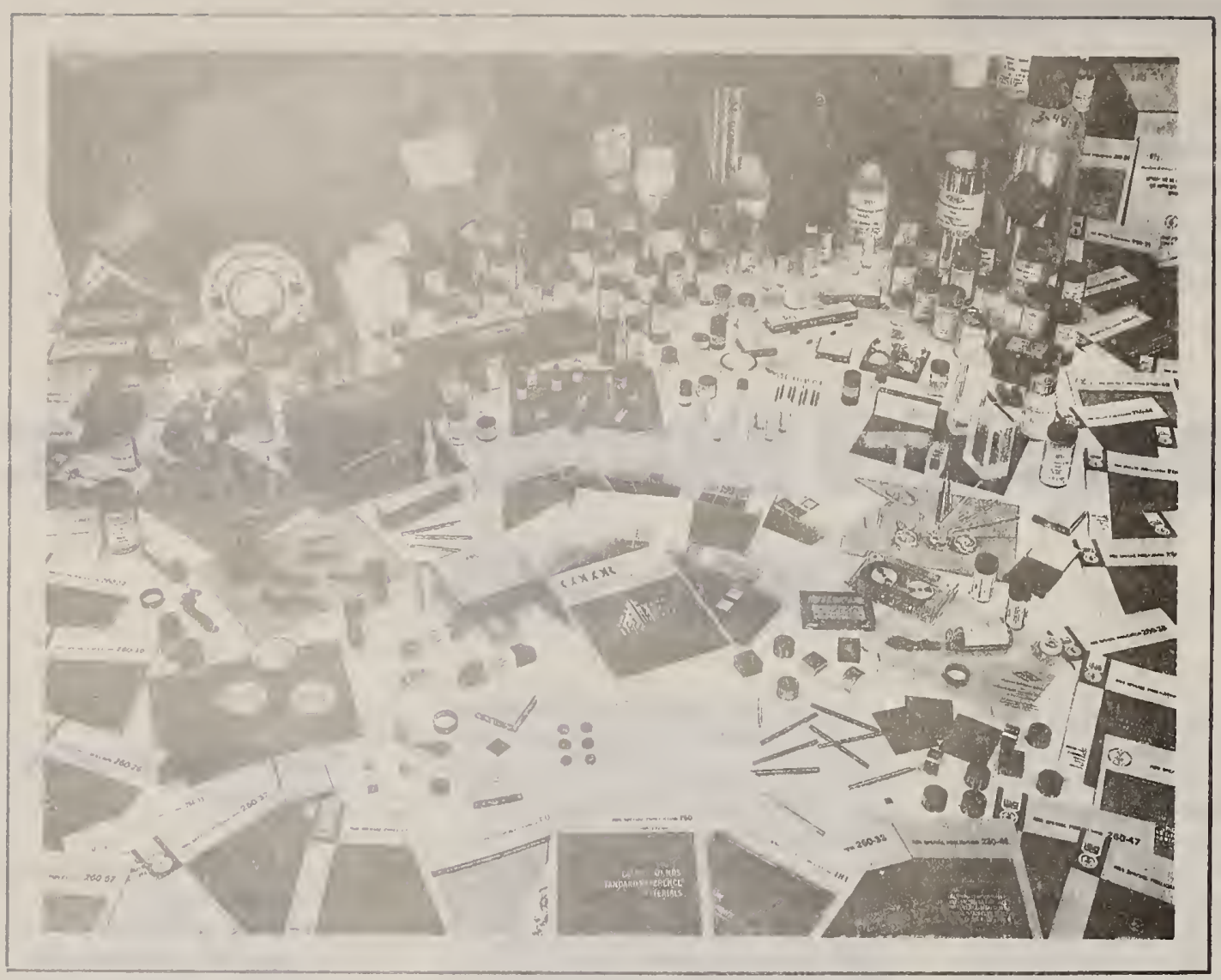

A panoramic display of approximately 300 of the nearly 900 different SRMs currently certified by NBS

tain SRMs, even in the face of strong technical demand. The $"$ are serious losses to the program and to the U.S technical community.

For the metals and ores (categor $1,2,3$, and 5) a good balance in inv tory has been maintained over the past 16 years, with gains in the number of types available in all categories except ferrous metals. In that category, the net decrease does not repre sent a serious technological shorifall. Rather, it results from eliminating some duplication and certifying mor elements in fewer materials to cover the same technological needs Espe cially since 1976, the Metals Resear Associate Program [conducted joint]. with the American Society for Testing and Materials (ASTM)] has played major role in meeting industrial need for metal reference mat ials. Th operation of ASTM sponsorıg Com mittees E-2, E-3, and E-16 in helpın to select and carry out metal certific tion projects has been 'e valuablo ensuring a strong inventor of me al reference materials.

ry decline should not present serious roblems is the metallo-organics category. There a number of pure materials have been dropped that were formerly available for synthesizing wearmetal-in-oil standards for individual lements. They are being replaced ith a few multielement-metal-in-oilmatrix SRMs that should serve the ame purpose.

In the nuclear and isotopic, radioactivity properties, and mechanical properties categories taken together, there has been a net decrease of 85 inventory types. In general, this reflects an attempt to develop benchmark SRMs covering only the most important parameters rather than to proide SRMs for every single point of inverest. This not only conserves the program's financial resources, but also provides additional opportunities for commercial suppliers of reference ma-

\section{ategury 25, engineering proper-} - color, will very likely disappear e next two years. Centroid color rts and color chart kits remain in category, and the technology to res ew them is no longer available at
The area of largest expansion during the past 16 years has been in biological/botanical and environmental categories (categories 10-12). These three categories had a combined gain of 40 types between 1966 and 1976 and a further gain of 64 types between 1976 and 1982. While some expansion may continue in the biologicals and botanicals, it seems unlikely that a similar growth rate will be maintained in the environmental categories. Good progress has been made in establishing benchmark environmental SRMs.

Overall, since 1976, about 280 new SRMs have been certified (excluding renewals), and about 380 types have been discontinued during the same period.

The fulfillment of customer orders from the SRM inventory was greatly accelerated during May 1982. At that time an improved warehousing of packaged SRMs was implemented and order processing was transferred to a real-time computer-based system. With order placement and printing of packing slips, labels, notifications, and invoices all automated, shipments of in-stock SRMs can now be made usu- 


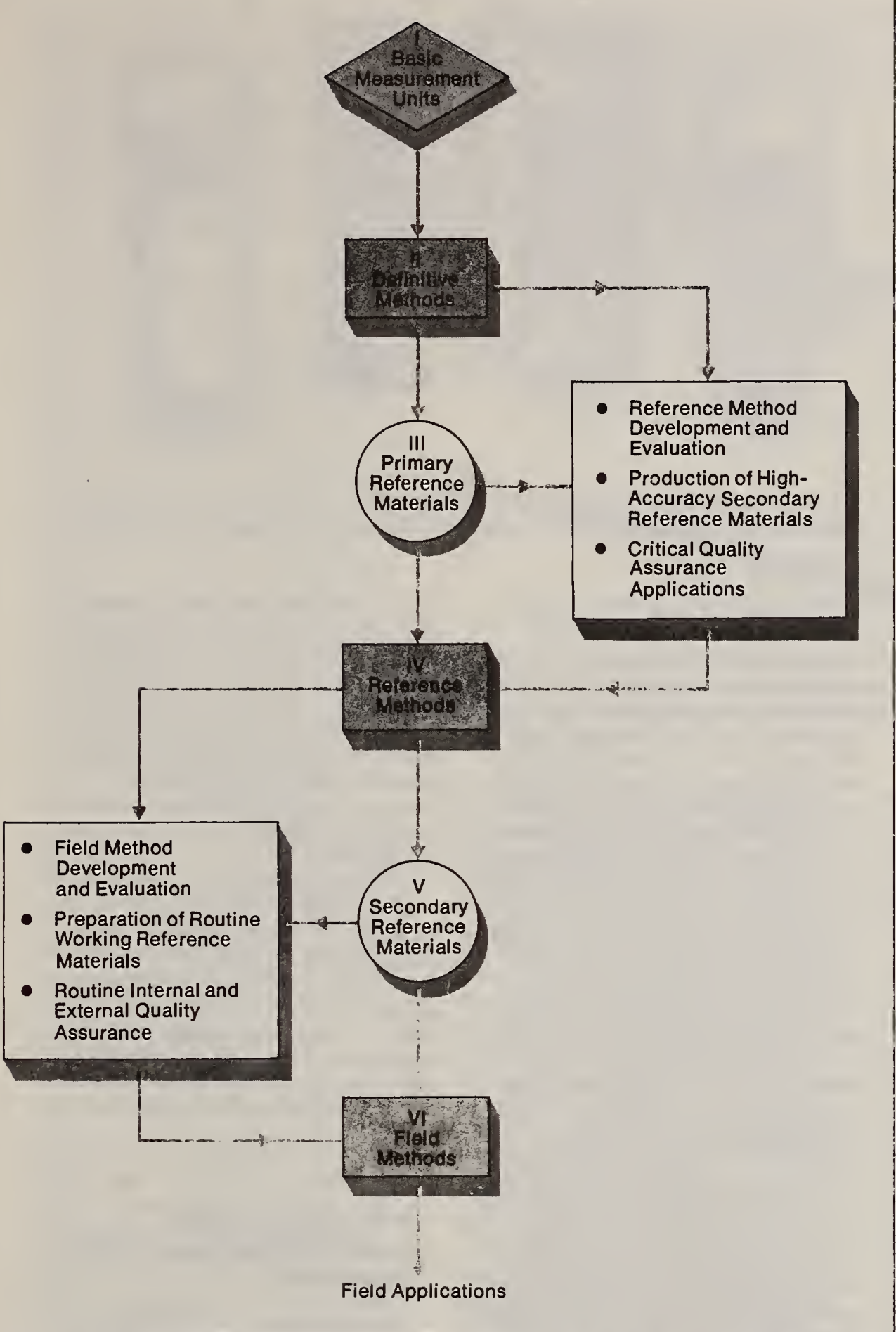

Flgure 1. An idealized accuracy-based measurement system, which illustrates the role of SRMs (primary reference materials) in transferring the accuracy inherent in definitive methods into widespread laboratory use. For a more detailed description, see Reference 10

ally within two days of receipt of order. This is in marked contrast to former processing times that averaged two to three weeks.

Further information regarding specific SRMs may be found in the cata$\log$ of NBS Standard Reference Materials (4) and in a recent annual report covering new developments (5). More frequent updates are published monthly in a column entitled "Reference Materials" (6). Periodic reports standards. The role of SRMs in an idealized systems approach to measurement accuracy is shown in Figure 1. As can be seen from the figure, SRMs are only one part of a larger picture. Also essential to obtaining accurate analyses are good methods, good laboratory practices, well-qualified personnel, and adequate quality assurance procedures.

Where possible, NBS certifies numerical values of the properties under investigation as accurate values. That is, they are the "true values" within the stated overall uncertainty limits. During the mid-1970s, considerable time and effort were invested in refining the technology of certification (8$12)$. These efforts have been continued into the 1.980 s with increased international participation (13-15).

In general, four major considerations are involved in certifying an SRM:

Homogeneity. It is essential that every subportion of a given lot be the same within the overall uncertainty limits provided. This is necessary to ensure that each user obtains a portion of the SRM which agrees, in values certified, with the certificate.

Stability. If the material changes with time (and certainly most materials do to some extent) it will eventually have "true values" that no longer agree with the values printed on the certificate. Increasingly, SRMs are provided with expiration dates, after which their certificate is not valid.

(For example, no clinical SRM is issued with a certificate valid for more than five years.)

Handling Procedures. Special procedures, such as cold storage, drying, and other preparation, may be necessary to the proper use of SRMs. Such instructions are now provided routinely when appropriate.

Certified Values. The importance of accurately analyzing materials so that "true value" numbers can be placed on the certificate is clear, but this is our most difficult job at NBS. We do not claim infallibility. Even though systematic errors in the measurements leading to certification are always investigated, later advances in the state of the art may uncover errors that were undetected at the time of the original work. Thus, NBS tries to provide conservatively stated uncertainties to allow for unknown systematic errors. Several techniques are especially helpful in the quest for certification accuracy.

First, although they may be much too costly for routine use, definitive methods (methods of the highest accuracy) are more closely linked to basic measurement units and thus reduce opportunities for error. Second, the agreement of several independent

(continued on p. $1235 \mathrm{~A}$ ) 
methods lends assurance to certilication. Further, agreement among several independent laboratories - using the same or different methods-provides additional reason for confidence. Assistance in certification is provided by many independent laboratories. Increasingly, the coordination of this assistance has been accomplished with the help of the American Society for Testing and Materials, through research associate agreements. There are such agreements in effect in the fields of metals and ores, glass, and particle metrology. Additionally, the cooperation of other associations has been most helpful. Some of those cooperating in the production of SRMs are the Atomic Industrial Forum, the Motor Vehicle Manufacturers Association, the American Iron and Steel Institute, the American Foundrymen's Society, and the Portland Cement Association.

Information on measurement methods used in SRM certification is frequently published in greater detail than can be given in the certificate, especially when the methods are novel or modified from standard practice. The NBS Special Publication 260 Series is dedicated to reporting progress in the technology of certification. Seventy-seven reports in this series have been prepared during the past 18 years. The first 49 reports were mentioned in the 1976 ANALYTICAL CHEMISTRY article (2). Now an additional 28 are categorized in Table II.

\section{International Progress}

The last decade has seen a large growth in reference materials activities, not only at NBS, but also within many other countries and multinational organizations. In the U.S., more than 250 new SRMs must be certified in the next five years, judging from requests and proposals already in hand at NBS. The worldwide demand for certification of new reference materials over the coming decade is probably numbered in the thousands. Considerable resources must be devoted to maintaining the supply of the thousands of reference materials already certified. No single organization has sufficient resources to meet these demands on a timely basis. Thus, greater international cooperation is essential to expedite certification of needed new reference materials and to reduce unnecessary duplication of efforts.

NBS continues to play an important role in international reference material activities through cooperative projects involving international standards organizations and professional societies, as well as through working arrangements with certified reference material producers in other countries and in multinational organizations.
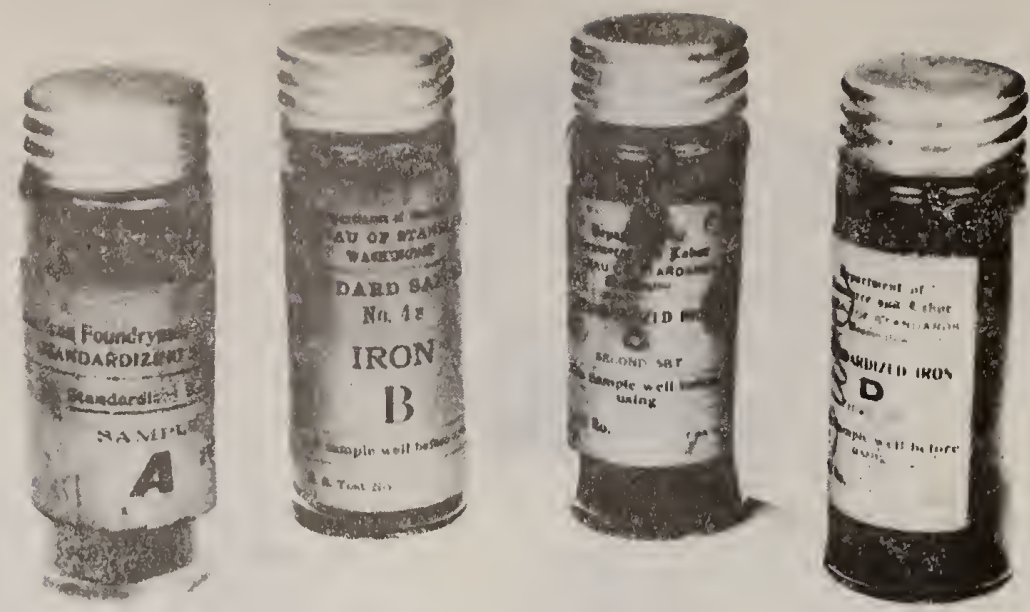

The first four SRMs certified by NBS in 1906 were these four cast iron compositional standards prepared in cooperation with the American Foundrymen's Society

During the past eight years, the International Organization for Standardization (ISO) has become very active in promoting communication and cooperation among reference material programs in various countries through the work of the ISO Council Committee on Reference Materials (REMCO), currently chaired by George A. Uriano. REMCO has recently published a series of documents intended to serve as guides to the certification and utilization of reference materials. One of the most important documents recently issued by ISO is an international directory of certified reference material producers (16), which identifies hundreds of producers of certified reference materials throughout the world. The directory was assembled largely through the efforts of J. Paul Cali, former chief of the Office of Standard Reference Materials. Another important project recently initiated under REMCO sponsorship in cooperation with ISO TC-69 on Application of Statistical Methods is the development of a guide describing statistical principles for the certification and use of reference materials. An international team of statisticians and chemists has been assembled to draft the document.

NBS has given extensive support to the International Union of Pure and Applied Chemistry (IUPAC) Commission I.4 on Physicochemical Measurements and Standards. This commission has published a series of recommendations for the selection and specification of reference materials for use in various types of physicochemical measurements. Recommendations of particular interest to analytical chemists include those on reference materials for thermal (17) and optical (18) properties and potentiometric ion ac- tivities (19). NBS is working closely with other international standardization bodies having active programs involving certified reference materials, including the European Economic Community, the International Organization for Legal Metrology, the International Federation for Clinical Chemistry, the International Atomic Energy Agency, and the World Health Organization.

NBS has also been engaged in a number of bilateral cooperative projects with foreign national laboratories that are engaged in the certification of reference materials. A series of interlaboratory comparison projects aimed at ensuring the compatibility of measurement methods among various reference material producers has been completed. For example, a series of

\section{Table II. Guide to NBS Special Publications on SRMs Since $1975^{\circ}$}

\begin{tabular}{ll} 
SRM subject matter & \multicolumn{1}{c}{$\begin{array}{c}\text { Serlal numbers } \\
\text { In 260 Serles }\end{array}$} \\
\hline Ferrous metals & $70,73,76$ \\
Information, sources & 57 \\
Glass and ores & 74 \\
Instrumental aspects & $51,54,59,62,64$,
\end{tabular}

$65,66,68,75$

Primary chemicals

53

Physical properties $50,52,55,56,77$

Polymers

58,61

Clinical and health $60,63,67,69$,

$$
71,72
$$

- For example, $\# 60$ in the second column refers to NBS Special Publication 260-60 (1978). Its title Is "Standard Reference Materlals: A Reference Method for the Determination of Sodlum In Serum." Full titles are llsted in the current SRM Catalog. 
analytical gas SRMs for use in environmental monitoring was exchanged with the French National Bureau of Metrology (BNM), and analyses were made by both countries on the other's reference materials to verify the certifications. NBS and BNM are also currently completing the joint certification of a set of octane rating reference materials.

Finally, NBS has also devoted considerable effort to aiding developing countries in establishing or improving reference material certification programs. During the past five years, scientists representing Brazil, the People's Republic of China, Hungary, and Egypt have worked at NBS for periods of up to one year to study NBS procedures for the preparation and certification of reference materials. Several of these countries have greatly expanded their reference material certification activities, partly as a result of NBS cooperation. The Institute for Technical Research in São Paulo, Brazil, now certifies over 30 metal composition reference materials. The People's Republic of China has recently formed a new Center for Reference Materials within the National Institute of Metrology in Beijing.

The greatly increased world wide demand for certified reference materials will require even more international cooperation during the coming decade. Improved information transfer and technology transfer will be essential to ensure that these demands are met in an efficient and timely manner.

\section{Recently Introduced SRMs}

Metals, Ores, and Minerals. Most metal, ore, and mineral SRMs developed in recent years are a joint effort with industry and ASTM. The justification for such SRMs is provided by industry, generally through a special ASTM Coordinating Committee for Standard Reference Materials (S-17). As for all SRMs, their justification includes evidence of need, unavailability of similar reference materials from other sources, and information concerning special requirements for the SRMs, e.g., chemical composition, homogeneity, and form.

Examples of a few especially significant industrial SRMs are described. A complete listing of available industrial SRMs is given in the NBS SRM cata$\log (4)$.

Tracealloy: Nickel-Base HighTemperature Alloy. SRMs 897-899 are certified for $\mathrm{Pb}, \mathrm{Se}, \mathrm{Te}$, and $\mathrm{Tl}$. The presence of these elements at trace concentrations in nickel-base alloys affects their performance in highstress high-temperature applications, such as gas turbines.

Unalloyed Copper Benchmark $S R M s$. Impurity elements and their

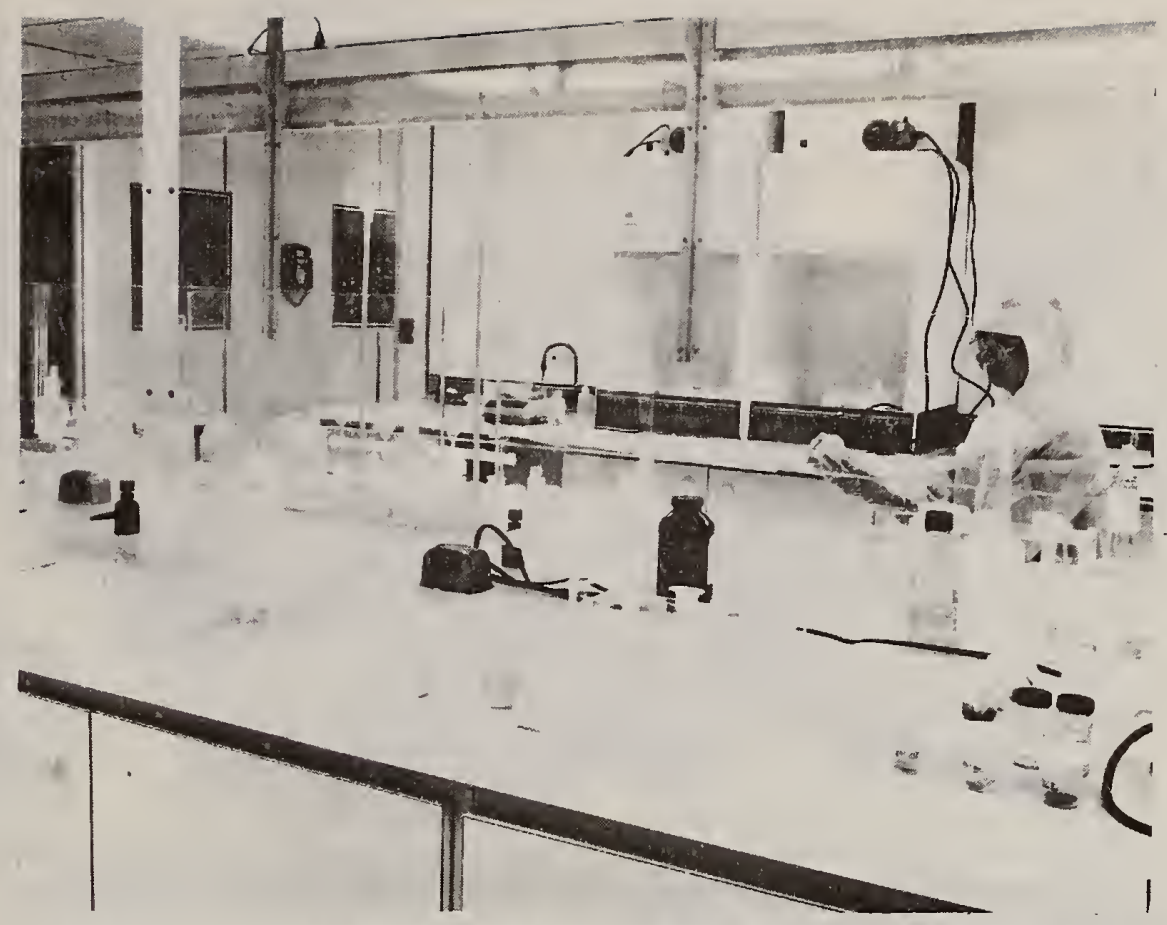

The ability to control analytical blanks due to external sources of sample contamination is an important requirement in high-accuracy trace analysis. Ellyn Beary is utilizing one of the NBS Clean Room Facilities for preparation of SRM specimens for trace analysis

concentration levels in refined copper have a profound effect on such properties as electrical and thermal conductivity, which in turn affects product performance in a number of energy-related applications. For example, the presence of as little as $50 \mu \mathrm{g} / \mathrm{g}$ of $\mathrm{Fe}$ in copper wire can reduce the electrical conductivity by as much as 4\%. Chemical composition specifications for unalloyed copper products have become so severe that disagreements among producers and consumers have resulted. Copper SRMs provide concentration ranges for approximately 13 trace elements.

Zirconium Metal and Zircaloy-4 Alloy. Because of its high-capture cross section for neutrons, the presence of hafnium in zirconium and its alloys adversely affects the operating efficiency of nuclear power plants. Therefore, hafnium must be reduced to $\mu \mathrm{g} / \mathrm{g}$ levels in these reactor-grade materials. However, the difficulty of determining trace concentrations of hafnium has led to disagreements between producers and users of such materials. Recently, a newly developed isotope-dilution spark source mass spectrometric procedure has produced results for hafnium in agreement with neutron activation analysis. This has enabled NBS to add hafnium to the certification of these materials.

Reduced Iron Ore (SRM 691). Reduced iron oxide is an important intermediate in the making of steel by the electric-furnace method. The production and certification of a stable and homogeneous reduced iron oxide reference material for metallic iron, total iron, and other elements have proven to be formidable problems during the last decade. NBS SRM 691 represents the first certified material of this kind. It supplements four additional iron ore SRMs.

Energy-Related and Environmental SRMs. Some constituents present in coal and other fuels are potentially injurious when released into the environment. These include elements such as mercury, cadmium, and lead; organic compounds present naturally in oil, such as polynuclear aromatic hydrocarbons (PAHs); and oil contaminants such as polychlorinated biphenyls (PCBs). A series of environmental SRMs was develnped to provide certified concentrations of environmentally important inorganic and organic constituents. The SRMs include fossil fuels, water, sediments, urban dust, and biological matrices. In addition, a series of gas mixtures and permeation tubes is available that is useful in monitoring stationary and mobile sources of pollutants. Special nuclear materials and radioactive SRMs have also been developed.

Coals-Bituminous and Subbituminous. Two coals are available that are certified for chemical composition including elements present at trace levels such as the priority pollutants, $\mathrm{Cd}$, $\mathrm{Cr}, \mathrm{Cu}, \mathrm{Ni}, \mathrm{Pb}$, and $\mathrm{Zn}$. The subbituminous coal (SRM 1635) is certified for 14 elements, the bituminous coal (SRM 1632a) for 19 elements.

Many of these elements are concentrated in the particulate fly ash. Al- 


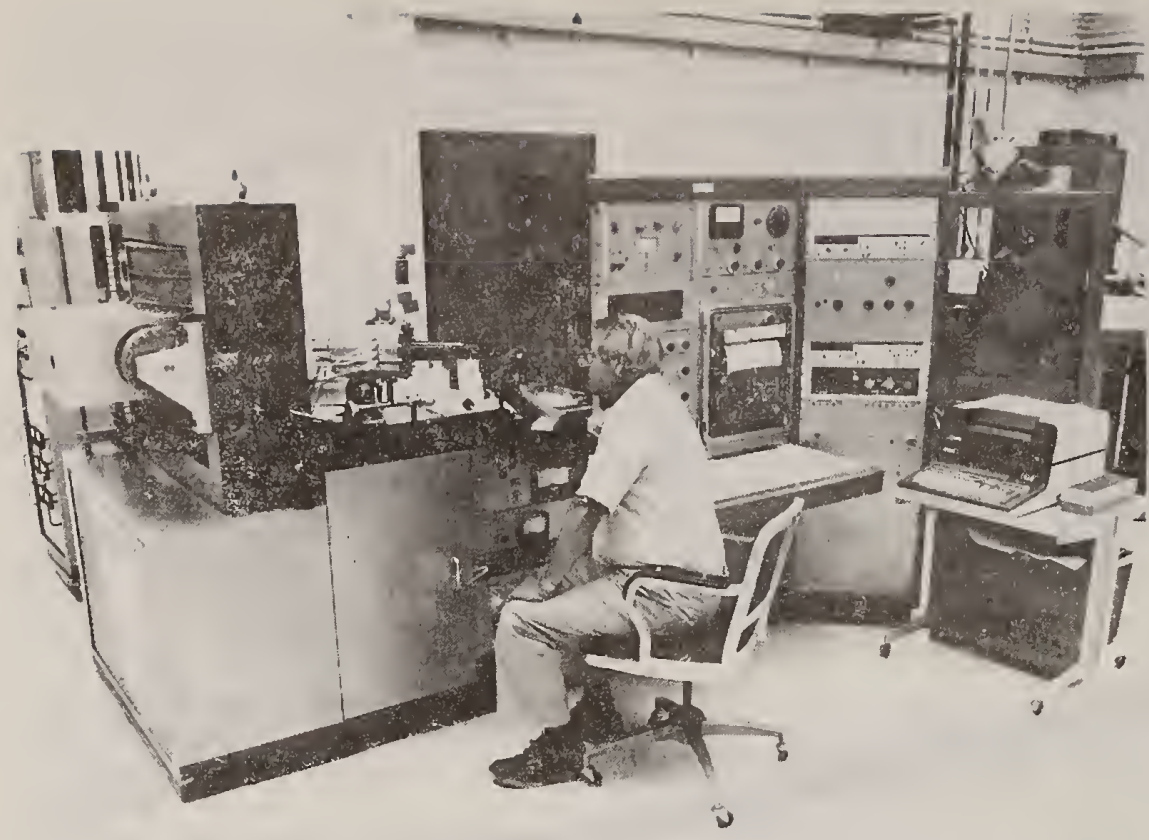

1. Lynus Barnes operates an NBS high-accuracy mass spectrometer used together with isotope dilution techniques for certification of inorganic constituents in a wide variety of SRMs

though fly ash can be removed by electrostatic precipitators, its storage and disposal have environmental consequences. Coal fly ash, SRM 1633a, which is certified for 20 elements, has been issued for use in validating data and methods for this material.

Fuel Oils and Reference Fuel. A series of residual and distillate fuel oils (SRMs 1619-1624) provides certified sulfur concentrations ranging from 0.1 to $5 \%$ nominal. A commercial "No. 6" residual fuel oil, certified for $\mathrm{S}, \mathrm{Pb}$, $\mathrm{Mn}, \mathrm{Ni}, \mathrm{Se}, \mathrm{Na}, \mathrm{V}$, and $\mathrm{Zn}$, is available for use in assessing the reliability of these analytical determinations. Reference fuels with certified concentrations of lead are also available.

Shale Oil. A shale oil SRM was developed primarily for evaluating the accuracy of analytical methodology in on oil matrix. Based on agreement of two independent methods, certified concentration values are provided for nine trace organic constituents of environmental concern, including fluoranthene, benzo[a]pyrene, perylene; and phenol.

Polychlorinated Biphenyls in Oil (SRM 1581). The widespread use, persistence, and reported toxic effects of PCBs caused the Environmental Protection Agency (EPA) to ban their manufacture and use under provisions of the Toxic Substances Control Act. Handling and disposal of materials containing $\mathrm{PCB}$ depend on the $\mathrm{PCB}$ concentration. Fluids containing 50 $\mu \mathrm{g} / \mathrm{g}$ or more of PCBs are subject to controlled disposal. To aid in analysis of such oils, SRM 1581 has been certified. It consists of Aroclors 1242 and
1260 present individually at $100 \mu \mathrm{g} / \mathrm{g}$ in motor oil and transformer oil. Additional base oil is supplied as a diluent.

Water. Five SRMs have been developed for the analysis of water-three for the determination of inorganic constituents and two for organic compounds. SRM 1643a simulates the elemental composition of natural fresh water. It was prepared by adding known amounts of 21 elements to high-purity water, including 17 at $\mathrm{ng} / \mathrm{g}$ (ppb) levels. Two additional SRMs for mercury at $\mu \mathrm{g} / \mathrm{g}$ and $\mathrm{ng} / \mathrm{g}$ levels in water have been especially prepared to assure stability.

Considerable effort has also been devoted to developing a new class of SRMs for use in determining trace toxic organics, such as PAHs. However, solutions containing known concentrations of PAHs in water are unstable. Therefore, an unusual system in the form of "generator columns" (SRM 1644) was developed to enable the user to accurately generate aqueous concentrations of three PAHsanthracene, benz[a] anthracene, and benzo[a]pyrene (20). These compounds represent three-, four-, and five-condensed-ring structures, reAccurate concentrations of these lowsolubility compounds, which range from 1 to $50 \mu \mathrm{g} / \mathrm{kg}$ (ppb), are difficult to achieve by other techniques.

Solutions of PAHs in acetonitrile are stable when present at higher levels. Accordingly, an acetonitrile solution containing known concentrations of 16 PAHs, identified as EPA priority pollutants, was prepared, ampouled, spectively, and are priority pollutants. and analyzed by high-performance liquid chromatography and gas chromatography. The PAHs are present at $\mu \mathrm{g} / \mathrm{mL}$ levels in SRM 1647. Because of the miscibility of acetonitrile with water, the SRM is particularly useful in fortifying aqueous samples. In addition to providing certified concentrations and estimated uncertainties for the PAHs, the certificate for SRM 1647 gives ultraviolet absorption data between 205 and $600 \mathrm{~nm}$ as an aid in identifying the compounds.

Sediments. Two new sediments have been developed-a river sediment (SRM 1645) and an estuarine sediment (SRM 1646). The concentrations of the environmentally important elements in the estuarine sediment are much lower than those in the river sediment, which came from a highly industrialized area. The estuarine sediment is also certified for nutrient elements and should prove useful to marine biologists.

Urban Dust. Two urban particulate SRMs are available. The certificate of analysis for SRM 1648, which was revised in 1982 to include additional characterization, lists certified concentrations of eight inorganic priority pollutants: arsenic, cadmium, chromium, copper, lead, nickel, selenium, and zinc. An additional six elements are certified, while noncertified values are provided for 22 elements.

In 1982, a second urban dust (SRM 1649), certified for five PAHs, was issued. The compounds, all priority pollutants, and present at $\mu \mathrm{g} / \mathrm{g}$ levels in the material are: fluoranthene, benz [a]anthracene, benzo[a]pyrene, benzo[ghi]perylene, and indeno[1,2,3-cd]pyrene. In addition, information is provided on the concentrations of 9 organic compounds, 24 elements, and 4 leachable anions.

Gas SRMs of Certified Composition and Permeation Devices. There are now more than 60 gas SRMs certified for use in analysis of gaseous pollutants. These SRMs provide a wide range of compositions of oxides of nitrogen, carbon, and sulfur and hydrocarbons in either an air or nitrogen matrix. Twenty-five of these SRMs were developed in a two-year cooperative program with the Motor Vehicle Manufacturers Association. The heavy demand for gas SRMs has resulted in NBS cooperating with EPA to establish a procedure for assuring traceability of commercially produced certified reference materials to SRMs from NBS (12).

NBS has under development a new series of organic constituent permeation tubes and cylinders. The first to be introduced will be benzene in nitrogen gas and a benzene permeation tube. 


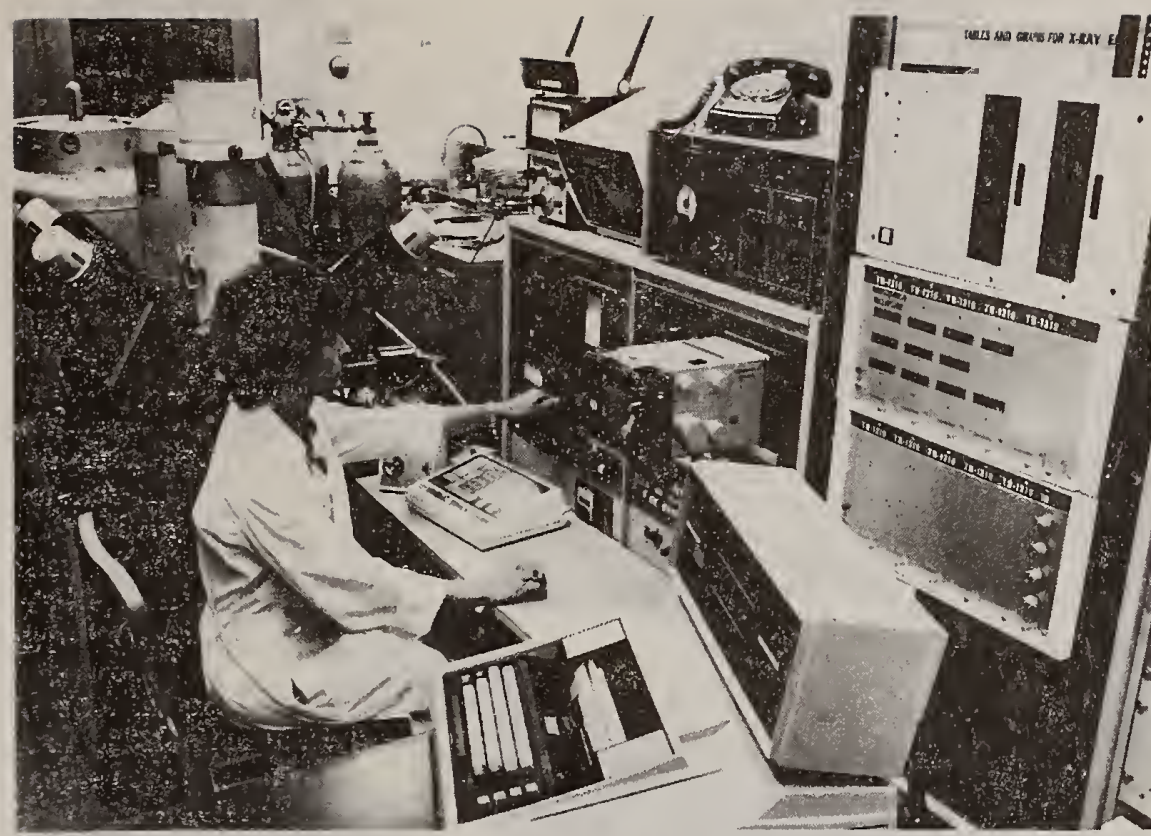

Ryna B. Marinenko operates an electron microprobe used for quantitative evaluation of microhomogeneity of SRMs such as SRM 470, mineral glasses

\section{Biological/Botanical Matrix}

SRMs. The importance of reliably determining elements in plant and animal tissues continues to increase as researchers seek to establish optimum levels for nutrient elements in the diet and to assess the effect of elements thought to be toxic.

Nine biological-matrix SRMs are now available from NBS to aid in assessing the accuracy of elemental analysis in biological and botanical matrices. The certificates of analysis for these SRMs list certified concentrations of nutritionally and environmentally important elements.

Four SRMs are available for use in assessing the accuracy of plant tissue analyses. They are orchard leaves (SRM 1571), citrus leaves (SRM 1572), tomato leaves (SRM 1573), and pine needles (SRM 1575).

Two animal tissue SRMs are available: oyster tissue (SRM 1566) and bovine liver (SRM 1577a) - a renewal of SRM 1577. SRM 1566 was developed because of concern about contamination of marine animals used as foods. A number of marine animals, especially bivalves, are known to concentrate heavy metals and other substances from their aquatic environment. Some species of oysters and mussels exhibit this property to such a marked degree that scientists have proposed their use as sentinel organisms for monitoring pollutant levels in coastal marine waters. Accurate data on the pollutant levels in such bivalves can be obtained efficiently by analyzing the samples relative to a similar marine animal tissue in which concentrations have been certified for the elements of interest.
The certificate of analysis for the new bovine liver material (SRM 1577a) lists certified concentrations for elements that were not certified in the original bovine liver. In all, 22 elments are now certified in SRM $1577 \mathrm{a}$.

Brewers yeast, SRM 1569, is certified for $\mathrm{Cr}$ at $2.12 \pm 0.05 \mu \mathrm{g} / \mathrm{g}$. Cr determinations are of special interest to nutritionists because $\mathrm{Cr}$ is an essential element and plays an important role in the maintenance of normal glucose tolerance.

A wheat flour (SRM 1567) and a rice flour (SRM 1568) have been characterized mainly for trace elements of nutritional and environmental interest. The chemical composition of cereal foods is of special interest to environmentalists, medical researchers, and food scientists because of the large consumption of such foods throughout the world. Because of the interest in the accumulation of $\mathrm{Pb}$ in food products, $\mathrm{Pb}$ was determined in the two flour SRMs.

Stabilized Wine. Disagreements have occurred regarding the ethanol content of wines. These differences may be attributable to discrepant analytical results among laboratories. Because of the difficulty of validating ethanol determinations, the American Society of Enologists suggested and cooperated in the development of a stabilized $18 \%$ ethanol wine SRM.

Clinical SRMs. A number of new clinical SRMs have been developed for use in determining the accuracy of clinical data, methods, and commercially produced reference materials; in calibrating instruments and testing their performance; and in correlating and comparing clinical data from laboratories using different methods and instruments.

The clinical SRMs may be classified into three general types:

- human serum matrix materials with accurately certified constituents; - high-purity organic and inorganic compounds for preparing solution calibrators or spiking matrix solutions; and

- instrument-performance SRMs.

NBS has certified three human serum SRMs. SRM 909 is certified for electrolytes and organic constituents at "normal" levels in human serum. At present, the certificate lists certified concentration values for calcium, chloride, cholesterol, glucose, lithium, magnesium, potassium, and uric acid. Urea and total protein have also been determined and their concentration values will be added to a revised certificate upon completion of the statistical evaluation. All of these constituents were determined using isotope dilution mass spectrometric procedures, considered definitive methods because of their high accuracy.

The certificate for SRM 909 also provides information-only values of the catalytic concentrations of seven enzymes. The enzymes, for which definitive methods are not available, were determined cooperatively by teams of experts using "best available" methodology. Where possible, methods of the International Federation of Clinical Chemistry or the American Association for Clinical Chemistry were used. The certificate provides outlines of the methods and the final assay reaction conditions and gives literature references.

A human serum matrix (SRM 900) certified for subtherapeutic, therapeutic, and toxic concentrations of four antiepilepsy drugs-phenytoin, ethosuximide, phenobarbital, and primidone-has also been issued. This SRM was developed in response to a survey indicating inaccurate drug levels being reported by the majority of laboratories surveyed (21). The certification of SRM 900 has been described in detail (22). SRM 1599 is a second human serum matrix that contains certified concentrations of two other widely used antiepilepsy drugs - valproic acid and carbamazepine. A number of clinically important organic and inorganic compounds certified for purity are also available.

In addition, there are miscellaneous clinical SRMs, such as a bovine albumin material in either a high-purity powder or a $7 \%$ solution form, which conform to applicable specifications of the National Committee for Clinical Laboratory Standards. SRM 938, 4- 
nitrophenol, was developed for use in spectrophotometric procedures where 4-nitrophenol is the chromogenic compound formed.

A summary of the technical specifications for over $30 \mathrm{NBS}$ clinical SRMs has been prepared (23).

SRMs for Thermometry, Spectrophotometry, and Fluorescence Spectrometry. Chemical reaction rates such as those involving enzymes are very sensitive to small temperature changes. Thus, accurate measurement of reaction temperature is an important step in the analytical procedure. For validating temperature measurements, a gallium melting point thermometric device (SRM 1968) is available with a certified melting point of $29.7723^{\circ} \mathrm{C}$. A clinical laboratory thermometer with calibrated points at $0^{\circ}, 25^{\circ}, 30^{\circ}$, and $37^{\circ} \mathrm{C}$ is also available.

Nearing completion is a rubidium melting point thermometric device for calibrating thermometers accurately near $37^{\circ} \mathrm{C}$.

SRMs have been developed to verify the accuracy of the transmittance and absorbance scales of spectrophotometers. The SRMs consist of glass filters (SRM 930d and SRM 2030), metal-on-quartz (SRM 2031), liquid filters (SRM 931c), and crystalline potassium dichromate for use in solution form as an ultraviolet absorbance calibrator (SRM 935). A crystalline potassium iodide of known purity (SRM 2032 ) is available for assessing heterochromatic radiant energy (stray light) in ultraviolet spectrophotometers below $260 \mathrm{~nm}$. The specific absorbance of an aqueous solution of $\mathrm{KI}$ is certified at eight wavelengths, in 5-nm intervals from 240 to $275 \mathrm{~nm}$. Stray light in UV spectrophotometers is assessed by comparing the certified values of specific absorbance to the absorbance values of aqueous solutions of SRM 2032 measured under conditions of known concentrations, pathlength, and temperature.

Didymium glass filters (SRMs 2010 and 2013) are available for use in calibrating the wavelength scale in the visible region of spectrophotometers having nominal bandwidths in the range of 1.5 to $10.5 \mathrm{~nm}$. The wavelengths of maximum absorption were determined with a high-precision spectrophotometer for 14 to 24 wavelengths in the range of 400 to $760 \mathrm{~nm}$. The instrument has a wavelength accuracy of $0.04 \mathrm{~nm}$.

For calibrating fluoresence spectrometers, a quinine sulfate dihydrate material (SRM 936) was analyzed for impurities, and a solution of SRM 936 in perchloric acid is certified for the relative molecular emission spectrum, from 375 to $675 \mathrm{~nm}$ for an excitation wavelength of $347.5 \mathrm{~nm}$.

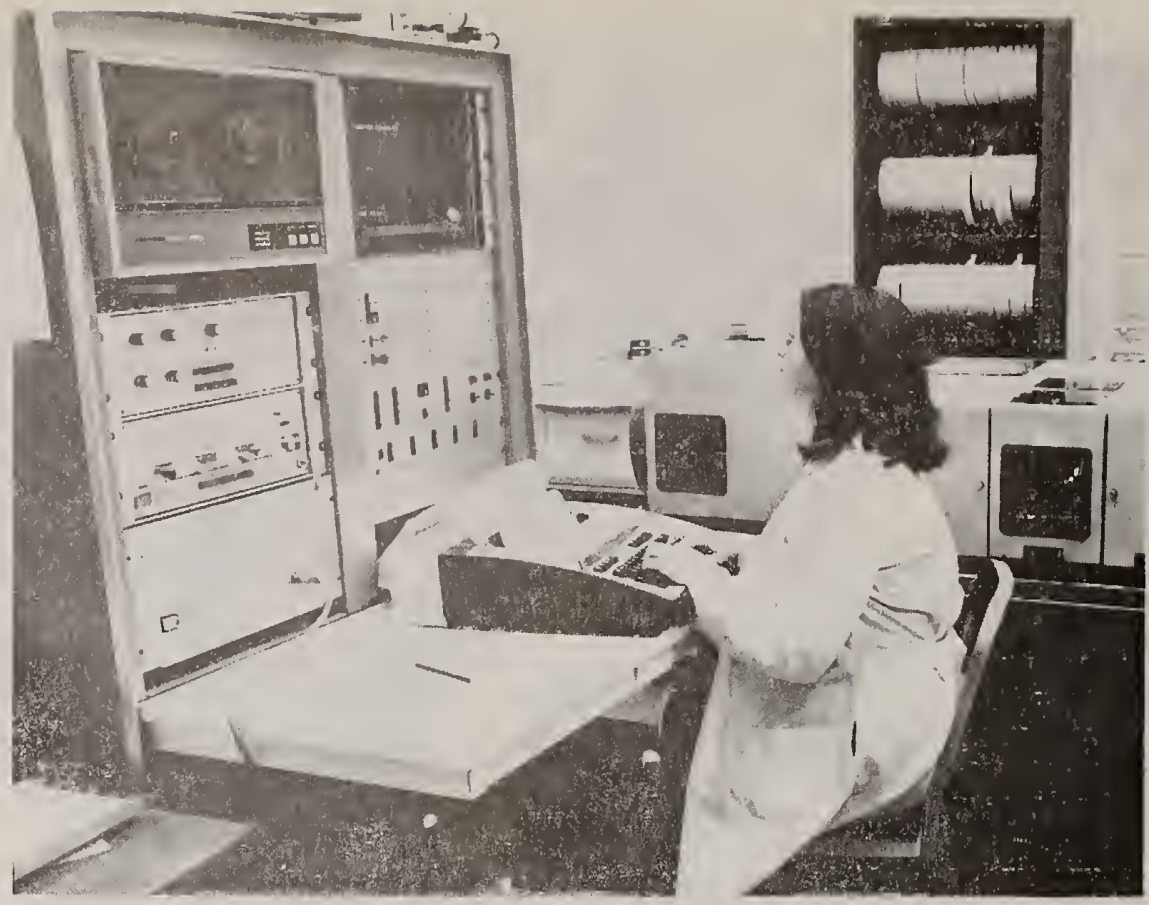

A Fourier transform infrared spectroscopy system is being operated by Reenie Parris. This technique is being used to determine the identity of individual PCB isomers in SRM 1581

Wear Metals in Lubricating Oil. Incipient engine failure can be detected by monitoring the concentrations of bearing metals in the engine oil. Two SRMs have been certified for use in the calibration of instruments and evaluation of methods for the analysis of engine lubricating oils for wearmetal content. The SRMs consist of metallo-organic compounds blended into a base oil at nominal levels of 100 ppm for SRM 1084 and 300 ppm for SRM 1085. The certificates of analysis will list certified concentration values for $\mathrm{Al}, \mathrm{Cr}, \mathrm{Cu}, \mathrm{Fe}, \mathrm{Pb}, \mathrm{Mg}, \mathrm{Mo}$, and $\mathrm{Ni}$.

SRMs for Microanalysis. SRMs have been developed to provide homogeneous materials suitable for quantitative microanalytical methods such as electron probe microanalysis, secondary ion mass spectrometry, spark source mass spectrometry, and laser probe analysis. They include: SRM 479, a single-phase alloy (austenitic) containing $71.0 \% \mathrm{Fe}, 18.3 \% \mathrm{Cr}$, and $10.7 \%$ Ni; SRM 480, a tungsten-20\% molybdenum alloy; SRM 481, goldsilver alloys; SRM 482, gold-copper alloys; SRM 483, an iron-3\% silicon alloy; and SRM 470, two glasses, certified for $\mathrm{SiO}_{2}, \mathrm{FeO}, \mathrm{MgO}$, and $\mathrm{CaO}$ (one is also certified for $\mathrm{Al}_{2} \mathrm{O}_{3}$ ).

In addition, two SRMs are available for use in evaluating the performance of scanning electron microscopes (SEMs). SRM 419 is for evaluating the SEM resolution; SRM 489b is for use in calibrating the SEM magnification scale to an accuracy of $5 \%$ or better within the range of 1000-20000X.

Radioactivity and Nuclear
SRMs. Radioactivity SRMs are available that are certified for the activity of the radionuclides. These SRMs include radiopharmaceutical SRMs, such as gold-195, and natural matrix materials such as a soil (SRM 4353) and a river sediment (SRM 4350b) collected from the vicinity of a nuclear reactor facility. The concentrations of fission and activation products in SRM 4350 b are higher than those found in other areas in the world. The radionuclides ${ }^{239} \mathrm{Pu},{ }^{240} \mathrm{Pu}$, and ${ }^{241} \mathrm{Am}$ are very homogeneously distributed, and the inhomogeneity is $3 \%$ or less for other radionuclides.

Other natural matrix radioactivity SRMs are being certified. They are: a human liver material (SRM 4352) certified for alpha-particle emitters; a Peruvian soil, which has very low levels of activation and fission products; and a lake sediment, which has a high content of organic matter and contains fission and activation products.

SRMs have been developed for use in nuclear energy production. These include: plutonium materials certified for $\mathrm{Pu}$ content, trace elements, and isotopic abundance; uranium materials certified for uranium concentration and isotopic abundance; a neutron density monitor wire SRM; and fission track glass standards. Some nuclear SRMs were developed in cooperation with the Department of Energy, New Brunswick Laboratory, and the University of California, Los Alamos National Laboratory. The New Brunswick Laboratory is now responsible for distributing nuclear SRMs. 


\section{Trends and Future Emphasis}

Until 1966, nearly all SRMs were compositional standards (primarily certified for bulk constituents or purity), designed for use in quality control systems during mining and manufacturing of raw and processed industrial materials. The SRM inventory primarily consisted of metal-bearing ores, metals and alloys, cement, glass, and inorganic chemicals.

In 1969, SRM development and production activities were involved in only six NBS technical divisions with over $90 \%$ of the production occurring in the NBS Analytical Chemistry Division. At that time, NBS management recognized that SRMs could serve as an important mechanism for iransferring the output of a broad spectrum of NBS measurement programs, including physical and engineering measurements as well as chemical measurements, to the user community.

By 1980, the Standard Reference Materials program was considerably strengthened through the participation of 23 technical divisions within NBS. This enabled NBS to increase the number of SRMs by over 500 (i.e., by nearly $100 \%$ in $14 \mathrm{y}$ ). Included were SRMs in many new areas such as computer technology, fire safety, forensic science, and radiopharmaceuticals, with recent emphasis on the two important areas of environmental and clinical measurements.

'Through the mid-1980s emphasis will be given to research and production projects leading to new SRMs certified for organic as well as inorganic constituents, particularly in natural matrix materials of environmental, clinical, or nutritional interest. Future emphasis also will be placed on inorganic ultratrace constituents and on species-specific certification. In the latter case, research problems to be resolved are formidable.

Another area of special emphasis during the next three years is the renewal of the SRM 1260 series for lowalloy steel composition. The current series of materials provides a foundation for quality control in steel production around the world. The renewal program, costing about $\$ 500000$, will provide enough additional SRMs to meet expected demand through the 1990s.

Microdimensional characterization, which will be a growth area for physical property SRMs, is also of special interest to analytical chemists. Here, small particles, some with diameters less than $1 \mu \mathrm{m}$, will be certified as calibrants for particle size measuring and counting apparatus. The certification of the chemical composition of surfaces (compositional mapping) is also an important need to be met in the ruture.

\section{References}

(1) "The NBS Standard Reference Materials Program," Anal. Chem. 1966, 38 (8), $27 \mathrm{~A}$.

(2) Cali, J. P. "The NBS Standard Reference Materials Program: An Update," Anal. Chem. 1976, 48, 802A.

(3) "Standard Reference Materials"; In formation booklet available from the Office of Standard Reference Materials, National Bureau of Standards, Washington, D.C. 20234 (1982).

(4) "Catalog of NBS Standard Reference Materials," 1981-83 ed.; NBS Special Publication 260; Government Printing Office: Washington, D.C.

(5) "1981 Annual Report-Office of Standard Reference Materials"; Uriano, G. A.; Rasberry, S. D., Eds.; NBSIR 812447; National Bureau of Standards: Washington, D.C., 1981.

(6) "Reference Materials"; Rasberry, S. D. Ed.; monthly column appearing in $\mathrm{Am}$. Lab. 12, 13, 14, June 1980 to present.

(7) Alvarez, R. "Report on Reference Materials and Standard Solutions," $J$. Assoc. Off. Anal. Chem. 1980, 63 (2); 1981, 64 (2); 1982, 65 (2).

(8) "Proceedings of the Symposium on Standard Reference Materials and Meaningful Measurement"; Seward, R. W., Ed.; NBS Special Publication 408; Government Printing Office: Washington, D.C., 1975.

(9) Cali, J. P. et al. "The Role of Standard Reference Materials in Measurement Systems"; NBS Monograph 148; Government Printing Office: Washington, D.C., 1975

(10) Uriano G. A.; Gravatt, C. C. "The Role of Reference Materials and Methods in Chemical Analysis," Anal. Chem. $1977,6,361$.

(11) Cali, J. P.; Reed, W. P. "The Role of NBS Standard Reference Materials in Accurate Trace Analysis"; NBS Special Publication 422; Government Printing Office: Washington, D.C., 1976.

(12) Hughes E. E.; Mandel, J. "A Procedure for Establishing Traceability of Gas Mixtures to Certain NBS SRMs"; NBSIR 81-2227; National Bureau of Standards: Washington, D.C., 1981.

(13) "Production and Use of Reference Materials"; Schmitt, B. F., Ed.; Proceedings of the International Symposium held at Bundesanstalt für Materialprüfung, Berlin 45 Federal Republic of Germany, 1980.

(14) "Terms and definitions used in connection with reference materials"; ISO Guide 30-1981 (E); Available from American National Standards Institute, 1430 Broadway, New York, N.Y. 10018 (1981).

(15) "Contents of certificates of reference materials"; ISO Guide 31-1981 (E); Available from American National Standards Institute, 1430 Broadway, New York, N.Y. 10018 (1981).

(16) "Directory of Certified Reference Materials (CRM): Sources of Supply and Suggested Uses"; International Organization for Standardization: Geneva; Available from American National Standards Institute, 1430 Broadway, New York, N.Y. 10018 (1982)

(17) Pure Appl. Chem. 1974, 40, 339.

(18) Pure Appl. Chem. 1974, 40, 463.

(19) Pure Appl. Chem. 1978, 50, 1485

(20) May, W.E. et al. "Proceedings of the Ninth Materials Research Symposium"; NBS Special Publication 519; 1979, p 219

(21) Pippenger, C. E. et al. Arch. Neurol. 1976, 33,351 .
(22) Keeder, U.J., el al. Anutune psy Drug Level Assay Standard"; NBS Special Publication 260-72; 1981.

(23) Seward, R. W.; Mavrodineanu, R. "Summary of Clinical Laboratory Standards"; NBS Special Publication 260-71; 1981.

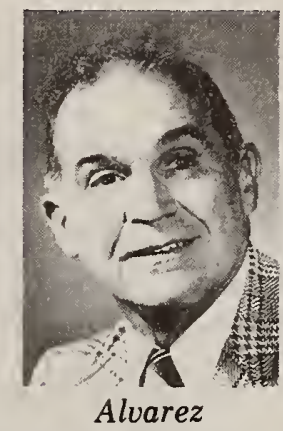

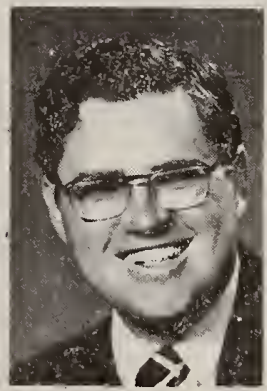

Rasberry

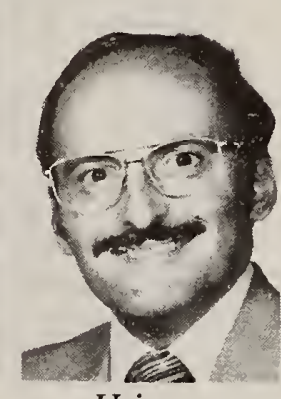

Uriano
Robert Alvarez is project manager for clinical, biological, and water pollution SRMs in the NBS Office of Standard Reference Materials. $\mathrm{He}$ obtained his BA degree in chemistry in 1942 from the College of the City of New York. As a research chemist, he has made a number of significant contributions to analytical chemistry, particularly in the areas of emission spectrometry, X-ray spectrometry, and isotope dilution spark source MS.

Stanley Rasberry obtained the $A B$ degree in physics from Johns Hopkins University in 1963 and is currently deputy chief of the NBS Office of Standard Reference Materials. One of the codevelopers of the RasberryHeinrich model to correct X-ray spectrā for interfering elements, Rasberry has also contributed to the development of about 50 SRMs.

George Uriano received his BA and MS degrees in physics from the University of Connecticut in 1961 and 1962, respectively. He is currently chief of the NBS Office of Standard Reference Materials. In his 20-year tenure at NBS he has led research projects involving the magnetic properties of materials and has also aided in the planning and management of major NBS programs involving materials science and chemistry. 


\section{TECHNICAL ACTIVITIES}

\subsection{Summary of New and Renewal SRM's}

Table 3. I summarizes the number of new and renewal SRM's produced in FY82 as distributed over major program categories. Fifty-three new and 110 renewal SRM's were completed with the largest number being in the metals, radioactivity and environmental categories.

Highlights covering the year's research activities are given in part four of this section. Issuances of new and renewal SRM's were recapped in section two: UPDATE 1982.

\subsection{FY82 SRM Sales Report}

Table 3.II summarizes SRM sales in terms of units, production income and total income for the year ending September 30,1982 . The gross income of $\$ 3,837,698$ was a record high for the program, exceeding last year's figure by $10.5 \%$. The 39,523 units sold is a decrease of $1.9 \%$ relative to last year.

During FY82, over 10,000 orders and 4,000 technical inquiries were processed. A comprehensive evaluation of all SRM's in inventory resulted in $\$ 163,500$ worth of material being obsoleted, which is less than two percent of the value of the inventory plus work-in-process. At the end of FY82, approximately 225,000 sales units of SRM's were carried in inventory with an asset value of $\$ 7,718,000$ (including other agency costs) and a market value of over $\$ 20,000,000$. 


\section{Table 3.I \\ SRM's Produced in FY 1982}

\begin{tabular}{|c|c|c|c|}
\hline Category & New & Renewals & Total \\
\hline \multicolumn{4}{|l|}{ INDUSTR IAL } \\
\hline Metals & 20 & 2 & 22 \\
\hline Nonmetals & 2 & 2 & 4 \\
\hline Chemicals/Rubber/Plastic & 3 & 5 & 8 \\
\hline Engineering & 1 & 28 & 29 \\
\hline Radioactivity & 4 & 28 & 32 \\
\hline Subtota 1 & $\underline{30}$ & $\underline{65}$ & $\underline{95}$ \\
\hline \multicolumn{4}{|l|}{ ENVIRONMENTAL } \\
\hline Gases & 7 & 8 & 15 \\
\hline Liquids/Solids & 6 & 15 & 21 \\
\hline Subtotal & $\underline{13}$ & $\underline{23}$ & $\underline{36}$ \\
\hline HEALTH & $\underline{1}$ & $\underline{6}$ & $\underline{7}$ \\
\hline SC IENCE / METROLOGY & $\underline{9}$ & $\underline{16}$ & $\underline{25}$ \\
\hline TOTALS & $\underline{\underline{53}}$ & $\underline{\underline{110}}$ & $\underline{\underline{163}}$ \\
\hline
\end{tabular}


Table 3.II

FY 82 SRM Sales by Category

Units

Total

Income *

I NDUSTR I AL

Metals

Nonmetals

Chemicals/Rubber/ Plastic

Engineering

Radioactivity/

Nuclear

Subtotals

ENV IRONMENTAL

HEALTH

SC IENCE / METROLOGY

GM/RM

TOTALS
12,527

4,563

4,810

6,895

1,704

30,499

$\underline{\underline{4,162}}$

$\underline{\underline{3,669}}$

$\underline{\underline{783}}$

$\underline{\underline{410}}$

39,523
931,308

318,401

359,850

659,123

353,766

$\underline{2,622,488}$

$\underline{\underline{718,523}}$

$\underline{369,405}$

$\underline{\underline{90,413}}$

$\underline{\underline{36,909}}$

$\underline{\underline{3,837,698}}$

${ }^{*}$ Includes income collected for other agencies and other factors. 


\subsection{Data Base Management System}

The new COBOL programs for use in processing SRM orders and inventory control was put on-line using the TI 990/12 minicomputer in March 1982. On May 3, 1982, testing was completed to the point that dual processing on the batch-loaded computer was discontinued and all customer service was operated in real-time mode. This had considerable impact on speeding up delivery to customers. Shipments which formerly had required two to three weeks after receipt of order are now being sent out in two to three days. The new system has also facilitated monitoring levels of packaged stock and a reduced stock-out rate has been observed.

Software other than customer support has also been developed. The new programs support management through better information regarding inventory trends and by keeping track of the information pertinent to SRiM project selection. Computer programs will be developed in FY83 to provide rapid tracking of the status of work in process for active projects.

\subsection{Highlights of Research Projects}

This section describes SRM research highlights during FY82. Thirty-five SRM research projects were active during the year in eighteen different NBS divisions. Rather than provide a complete review, some projects are highlighted here.

\section{. 1 Radioactivity Research}

B. M. Coursey, A. T. Hirshfeld, F. J. Shima and J.M.R. Hutchinson

Nuclear Radiation Division

Center for Radiation Research

An activity calibration of selenium-75 by $4 \pi e-\gamma$ coincidence of anticoincidence methods is complicated by the presence of an 18-ms isomeric level. Present apparent discrepancies with the calibrations of other national standardizing laboratories can be traced to different estimates of the extra delayed counts due to decays from this level. Preliminary measurements with our anticoincidence system have shown that this contribution can be measured directly by using very long, accurately known dead times to block a calculable fraction of the extra counts. This method is now being applied in an intercomparison of activity measurements with $\mathrm{OMH}$, Hungary.

The reproducibility of the gaseous mixed-radionuclide SRM 4310 was checked with a germanium gamma-ray spectrometry system. The SRM is prepared by mixing krypton-85, xenon-127, and xenon-133g, with each component separately measured as to 
activity with a calibrated ionization chamber. For two prototype sources and two of the SRM's, the gamma-ray-emission rates at six energies were measured with the spectrometry system to check the quantitative mixing of the three gases. The detection efficiencies at each energy were calculated and found to have standard deviations of the mean from 0.29 to 0.92 percent, sufficient to demonstrate the quantitative metering of the gases within the counting statistics possible. Additionally, an efficiency curve was fitted to the data, after cascade summing was corrected. This curve allows a more accurate assay of a xenon-131m impurity, and should prove useful for the investigation of short-lived noble gases in this bulb geometry.

Developmental work was completed on the Columbia River Sediment and Peruvian Soil and SRM's of both were issued in FY82. The transuranic radionuclides were found to be extremely homogeneous in both materials and could be extracted by acid leaching methods. Peruvian soil should be used by many people as a blank, for the man-made radioactivity concentrations were found to be two orders of magnitude below those found in the columbia River material. For the Peruvian Soil, in addition to certification of 11 radionuclides and non-certified measurement of 5 radionuclides, trace element concentrations for 57 elements are given, based on IAEA intercomparison results.

.2 Surface-analysis Measurements

\section{J. Powe 11}

Surface Science Division

Center for Chemical Physics

(1) Measurement of Absolute Ion Sputtering Yields

(J. Fine and T. D. Andreadis)

The principal aim of this work is to obtain absolute sputtering yields of $1-5 \mathrm{keV}$ ions on well-characterized elemental samples in order to improve accuracy of depth-profiling measurements by current surface-analysis methods. The accuracy of depth-profiling measurements is at present limited by the unavailability of accurate, reliable sputtering yield data and by the lack of knowledge of the topographical and morphological effects produced by ion bombardment.

The use of quartz-oscillator techniques to measure mass loss due to ion bombardment can result in very accurate determinations of ion-sputtering yields. In addition to the third-harmonic oscillator method developed at NBS, another system (operating in the fundamental mode) has been developed at the J. Stefan Institute in Ljubljana, Yugoslavia as part of a joint U.S./Yugoslavia program and is presently in operation. 
Measurements are being made using the quartz-oscillator facilities in Ljubljana to determine absolute sputtering yields of $\mathrm{Ni}$ and $\mathrm{Cu}$ using multilayered thin-film targets. These films are similar in structure to the $\mathrm{Ni} / \mathrm{Cu}$ Standard Reference Materials we recently have produced and this yield data will form part of our SRM characterization. Preliminary results indicate that the sensitivity of the method is quite adequate for determining the yields of $\mathrm{Ni}$ and $\mathrm{Cu}$, metals for which the measured yields differ by only about 10 percent.

This type of yield determination will be extended to all of our SRM materials ( $\mathrm{Ni}, \mathrm{Cu}, \mathrm{Ag}, \mathrm{Ta}_{2} \mathrm{O}_{5}$ ) and will also be made using the actual SRM structures. Similar measurements will be made at NBS with our third-harmonic method on these SRM's as well as on in-situ prepared elemental targets. Comparison of results obtained by both systems will allow assessment of the absolute accuracy of the yield measurement.

(2) Development and Production of Standard Reference Materials (J. Fine, T. D. Andreadis and F. Davarya)

The objective of this project is to develop standard reference materials that would allow convenient determinations of ion-beam sputter-removal rates in commonly used surface-analysis instrumentation. Thin film reference materials of known thickness would be used to calibrate ion-gun current densities for particular operating conditions. This information together with sputtering-yield data for a range of materials would establish depth scales in the measurement of depth profiles.

As part of a joint U.S./Yugoslavia program between J. Fine at NBS and B. Navinsek at the J. Stefan Institute in Ljubljana, three prototype thin film structures have been fabricated by sputter-deposition in Yugoslavia: 1) a thin film oxide of tantalum produced by reactive sputter deposition onto an in-situ sputtered silicon substrate, 2) a multilayered $\mathrm{Ni} / \mathrm{Cr} / \mathrm{Ni} / \mathrm{C}$... thin-film structure where the layers are about the same thickness $(\sim 70 \mathrm{~nm})$, and 3 ) a multilayered $\mathrm{Ni} / \mathrm{Ag} / \mathrm{Ni} / \mathrm{Ag} . .$. structure where the Ag layer is considerably thinner than the $50 \mathrm{~nm} \mathrm{Ni}$ layer. These structures were also deposited onto quartz oscillators so that sputtering yield measurements can be obtained by the mass-loss method. Sputter depth-profile analysis using Auger spectroscopy and $x$-ray fluorescence has been completed on the $\mathrm{Ni} / \mathrm{Cr}$ system; this work has demonstrated the suitability of this material for use in sputter-profile calibration. The $\mathrm{Ni} / \mathrm{Ag}$ system, on careful analysis, has been shown to be subject to sputter-enhanced Ag surface segregation which can alter its depth distribution (see (3) below). A modified $\mathrm{Ni} / \mathrm{Ag}$ thin film structure was fabricated incorporating a much thinner Ag film ( $3-5 \mathrm{~nm})$ in order to take advantage of the Ag segregation to improve the interface resolution of these Ag "marker" layers. 
In addition to the analysis of these materials at NBS, some 20 sets of the three thin-film structures have been distributed through ASTM Committee E-42 on Surface Analysis. Results of these measurements, made by a variety of techniques (Auger-electron spectroscopy, secondary-ion mass spectroscopy, Rutherford backscattering spectroscopy, and proton-induced $x-r a y$ emission) to characterize the uniformity, periodicity, thickness, and stoichiometry of the films and their interfaces are in good agreement with those obtained at NBS. In collaboration with Drs. D. Simons and $M$. Brown of the Naval Surface Weapons Center at White Oak, Md., Rutherford backscattering spectroscopy and proton-induced $x-r a y$ emission are being evaluated for use in the non-destructive analysis of a large number of specimens of the actual SRM production.

Using the sputter-deposition facility at the J. Stefan Institute in Ljubljana, a stock of thin-film SRM's has been fabricated. About 200 sets, each consisting of four different structures ( $\mathrm{Ni} / \mathrm{Cr}, \mathrm{Ni} / \mathrm{Ag}, \mathrm{Cr} / \mathrm{Cr}_{2} \mathrm{O}_{3}$, and $\mathrm{Ta}_{2} \mathrm{O}_{5}$ ) will be available for distribution through NBS. Characterization of these specific materials will be necessary in order for NBS to certify their structure and thickness.

(3) Sputter-Induced Surface Segregation at $\mathrm{Ni} / \mathrm{Ag}$ Interfaces (J. Fine, T. D. Andreadis and F. Davarya)

The analysis of solid/solid interfaces by ion-beam sputter profiling in conjunction with surface analysis can result in a significantly broadened composition-depth distribution of the sputter interface. Various mechanisms exist that are responsible for this interface broadening and include recoil implantation, cascade mixing, preferential sputtering, topographical changes, and sputter-enhanced surface segregation (and diffusion) along point defects. The role of this last mechanism is least understood since very little experimental data exists that shows what effect it can have on interface widths obtained at $20{ }^{\circ} \mathrm{C}$. A better understanding of this type of diffusion would certainly enhance the ability to interpret sputter depth-profile data and thus to obtain a more quantitative characterization of surfaces and interfaces.

(1) We have found that once ion bombardment (with $1-5$ keV Ar ions) of a Ni/Ag thin-film interface has produced a metastable solid solution, Ag will segregate to the surface. This segregation can be observed to take place after the ion bombardment has been stopped.

(2) Our observation of the Ag segregation kinetics, performed using Auger spectroscopy in real time at $20{ }^{\circ} \mathrm{C}$, shows that the Ag surface coverage exhibits a time ( $t$ ) dependence proportional to $[1-\exp (-t / \tau)]$, the time constant $(\tau)$ having a value of a few minutes. Such kinetic measurements, which we believe to be unique, were done as a function of Ag concentration and ion energy and indicate that the segregation can be 
attributed to enhanced Ag diffusion associated with defects produced by ion impact.

(3) The observed interface profile is dependent on the Ag diffusion rate (which is concentration-dependent) compared to the sputtering rate. These results clearly demonstrate that sputter-induced diffusion can affect depth-profile measurements.

Future work will include investigation of the segregation kinetics of a very-thin $\mathrm{Ag} f \mathrm{flm}(\sim 3-4 \mathrm{~nm})$ sandwiched between two thicker $\mathrm{Ni}$ films to further elucidate the point-defect diffusion mechanism ( $r$ andom-walk model).

(4) Quantitative Sputter Depth-Profiling of Surfaces

(J. Fine and T. D. Andreadis)

The depth-profile analysis of ion-bombardment-induced surface segregation of $\mathrm{Ag}$ at $\mathrm{Ni} / \mathrm{Ag}$ interface is an example of applications requiring special Auger techniques. Because of the rapidly changing surface composition with time, we developed a computer-controlled rapid-sequential mode of Auger data acquisition (N(E)) that acquired and stored three spectral regions of interest (with backgrounds) in 20 seconds. Background subtraction methods were developed to insure high accuracy, especially for Auger lines of low energy ( $<75 \mathrm{eV}$ ).

. 3 Chemical Thermodynamics Measurements

\section{S. Abramowitz}

Chemical Thermodynamics Division Center for Chemical Physics

(1) Variation of the Heat of Combustion of SRM Coals with Time (D. R. Kirklin)

Standard Reference Materials 1632 a and 1635 are bituminous and sub-bituminous coals, respectively. These coals are issued by the NBS office of Standard Reference Materials for use in calibrating instruments and checking analytical procedures employed in the determination of trace elements in fossil fuels. Commercial laboratories need a sample with a known heat of combustion to evaluate their calorimetric procedures. Since the long term chemical stability (i.e., >1 yr.) of powdered coals has not been rigorously established, the certification of the heat of combustion of coals required a study of the chemical stability of coals.

The heats of combustion of SRM coal samples 1632 a and 1635 were measured in 0ctober 1979, April 1980, June 1981, and May 1982. Total decreases of approximately 0.88 percent and 1.51 percent were observed for SRM 1632 a and SRM 1635, respectively, over the three year period. The observed decreases are believed to be due to the slow oxidation of coal sample upon storage under laboratory conditions. 
Certified heats of combustion are badly needed by commercial testing laboratories. Since the annual decrease in the heat of combustion of coal samples is less than the ASTM recommended intralaboratory repeatability of approximately 0.5 percent, the SRM coal samples can be certified. However, the certificates must be updated annually.

(2) Sulfur, Heating Value, Ash and Moisture in SRM Coals 2682 , 2683, 2684 and 2685 (D. R. Kirklin, J. C. Colbert)

During fiscal year 1982, gravimetric sulfur determinations have been carried out for the four SRM Coals: 2682, 2683, 2684 and 2685. The coals will be certified for amounts of sulfur with approximate values of 0.5 percent, 2.0 percent, 3.0 percent and 4.5 percent, respectively. Since combustion of the coal samples is required for this gravimetric method, the heat of combustion of each coal has also been determined and is being submitted as part of the report of test to the office of standard Reference Materials. Measurements for moisture and ash content have also been made.

(3) Re-evaluation of the Heat Capacity of Alumina, $\mathrm{Al}_{2} \mathrm{O}_{3}$ (D. A. Ditmars)

Re-evaluation of the new NBS low-temperature data for SRM $720\left(\alpha-\mathrm{Al}_{2} \mathrm{O}_{3}\right.$, a heat capacity standard) were completed and this data was incorporated along with existing NBS

high-temperature heat capacity data for this SRM into a new NBS Certificate for SRM 720. The original experimental heat capacity data for SRM 720 in the range 1200-2500 K which had not been published previously (though they appeared in smoothed form in the certificate) were included in a publication describing this updating of the NBS SRM 720 certification.

(4) Re-evaluation of the Specific Heat of Aluminum, Al (D. A. Ditmars)

The specific heat of aluminum(s) has been measured at NBS in cooperation with a guest worker from Brock University, ontario, Canada. NBS SRM 44f, a specimen of 99.9995 percent purity, maintained by 0 SRM as a temperature standard (MP. $660.3{ }^{\circ} \mathrm{C}$ ) for IPTS -68 was the material investigated. The NBS data has been analyzed. It agrees very well with published low-temperature heat-capacity data for aluminum. Significantly, it also agrees much better than existing high-temperature specific data with a recently published theoretical, lattice-dynamical calculation of the heat capacity of aluminum(s) which explicitly includes anharmonic effects. This theoretical calculation had been carried out for the general case of fcc metals with several assumed forms for the $\underline{V}$ pair long range potential. 
The excellent agreement obtained in this instance between experiment and theory provides strong support for the validity of the assumed potentials and the calculation scheme used in the fcc case. Thus, a starting point has been provided for theoretical analysis of the high-temperature heat capacity data of bcc metals. Previous measurements at NBS had confirmed an unusual increase in the heat capacity of the bcc metals molybdenum and tungsten near their respective melting points.

(5) Evaluation of a Proposed Refuse Derived Fuel Reference Material (E. S. Domalski and J. C. Colbert)

A synthetic refuse derived fuel (RDF) was prepared and evaluated as a possible standard reference material for RDF. The synthetic RDF was composed of $80 \%$ cellulose, $15 \%$ silica, and $5 \%$ alumina. The particle size of all components was less than $50 \mu \mathrm{m}$. The heat of combustion, ash content, and moisture content was measured by 12 independent laboratories which were familiar with working with RDF. A statistical analysis of the within laboratory repeatability and the between-laboratory reproducibility was at about the same level as observed for SRM coal 1632a. As a result of this study, the ASTM E38.01 Subcommittee on Energy of the parent ASTM E38 Committee on Resource Recovery concluded that the NBS prepared synthetic RDF would make a good Standard Reference Material for RDF.

.4 Measurement of $\mathrm{pH}$

\section{W. F. Koch and G. Marinenko}

Inorganic Analytical Research Division Center for Analytical Chemistry

The measurement of $\mathrm{pH}$ is one of the most common analytical measurements performed both in the field and in laboratories around the world. Its application cross-cuts many disciplines including analytical chemistry, biology, medicine, material science, and nuclear chemistry, as well as a variety of environmental and energy projects. The concept of pH can be described in the strictest theoretical sense; however, the realization of the $\mathrm{pH}$ (the actual measurement) is possible only in the practical sense and, at present, must be based on quasi-thermodynamic foundations. This in no way detracts from the usefulness of the measurement, but it does make it highly dependent on the standards used to define the pH scale. The operational pH scale used in the United States and in much of the world is defined in terms of a series of standard buffer solutions issued and certified through the office of standard Reference Materials.

In order to maintain the standards in this important area of chemical metrology and to expand the utility and applications of pH measurements, a new high accuracy pH/potentiometry facility has been established. Construction of the facility is complete 
with the acquisition and assembly of the critical elements and instruments. A large controlled-temperature water bath which is used to thermostat the $\mathrm{pH}$ measurement cells is operational over the range 0 to $50{ }^{\circ} \mathrm{C}$. The accurate measurement of the bath temperature $\left( \pm 0.01{ }^{\circ} \mathrm{C}\right)$ is obtained through the use of a calibrated quartz thermometer. The quartz thermometer provides the accuracy required for pH research along with the flexibility and convenience that is unobtainable with platinum resistance thermometers.

The emf measurements are made with a calibrated digital voltmeter interfaced to the $\mathrm{pH}$ cells and to standard weston cells through a panel of hermetically-sealed reed switches. These switches were chosen for their low noise characteristics, low contact resistance, and null leakage current. A digital barometer, calibrated versus the working standard of pressure at NBS, is used to ascertain the pressure of hydrogen gas in the $\mathrm{pH}$ measurement cel1.

Several configurations of silver/silver chloride reference electrodes have been prepared for use in the hydrogen cells without 1 iquid junctions. These have been tested for physical and chemical stability, reproducibility, temperature coefficient and hysteresis, all parameters critical to accurate pH measurements. Considerable differences have been observed among the potentials of the various types of electrodes prepared on a silver wire support is excellent $( \pm 0.05 \mathrm{mV})$. The classical configuration using a platinum wire as the support performed less satisfactorily. Additional research is needed to elucidate these variations. Preliminary pH measurements have been made on solutions of dilute acids and of standard buffer materials. Measurements leading to the certification of renewal SRM pH and pD buffer materials, which are now in short supply, will commence in FY83. Automation of the facility for routine measurements is anticipated.

In addition, research is proposed to link the existing pH scale directly to a fundamental physical constant, specifically the Faraday. This will be accomplished through the use of high accuracy coulometry to determine, on an absolute basis, the hydrogen ion content of dilute solutions of highly purified mineral acids. These solutions will then be systematically compared with the primary standard buffer materials which now serve to maintain the NBS practical pH scale. A thorough examination of reference electrodes and liquid junction potentials will be a necessary part of this endeavor.

Future applications of this new pH facility will include the preparation of accurate $\mathrm{pH}$ standards to assure quality in analytical measurements and the expansion of the utility of the NBS pH scale as both a practical and a theoretical analytical tool. An important goal of this program is to produce and distribute pH standards which simulate the varying matrices and ionic strengths encountered in solutions such as acidic precipitation, body fluids, and seawater. 


\section{L. Barnes and P. A. Morales}

Inorganic Analytical Research Division

Center for Analytical Chemistry

The objectives of this project are to design and construct the instrumentation and develop the methodology for the determination by isotope dilution mass spectrometry of the concentrations of elements or compounds which normally occur as gases. The first application of the technique is intended to be the determination of the concentration of $\mathrm{CO}_{2}$ in a set of Standard Reference Material gases.

A 12 -inch radius, $90^{\circ}$ deflection mass spectrometer for the measurement of gases has been designed and constructed. The instrument contains an electron impact (EI) source for ionization. This source is controlled by a newly designed emission regulator which provides an electron energy of $0-100$ volts and an emission current of $0-1000$ A stable to better than $1: 10^{6}$.

The instrument also has a unique triple collector adjusted to collect ion currents at masses 44,45 , and 46 , simultaneously. The collector used a collimated beam design which, to a large extent, removes the effects of beam scattering and stray electron production. The measuring system employs two cary 401 electrometers and a NBS designed amplifier. The outputs of the amplifiers are fed to a pair of ratio digital voltmeters such that the ratios at masses $45 / 44$ and $46 / 44$ are obtained direct $1 y$.

The instrument is now in operation in a manual mode and final adjustments are being made in the measurement system.

A new sainple preparation and inlet system has also been designed and constructed. The system uses a dual (sample, standard) viscous flow inlet system and is currently designed for twelve samples but may be easily expanded to a much larger number.

The inlet system, designed for automatic, computer controlled operation is being used in a manual mode. The interface for computer control has just been completed and, after testing, will be put into operation. The components for the gas mixing system needed for isotope dilution analysis are currently being designed with the basic vacuum system and supports completed and in place.

During the first quarter of FY83, the system for isotope dilution analysis should be completed and assembled. Also, during this period the instrument and inlet system automation should be completed, installed, and tested. During the second quarter, the calibration of the measuring system will be completed and applied to the measurement of the isotopic ratios 
of a series of well defined reference materials. The initial isotope dilution measurements will be made during the third quarter, and during the last quarter of FY83 this measurement technique will be applied to the set of SRM's on which isotopic ratio measurements had been previously made.

$6 \quad$ Gases in Metals

B. I. Diamondstone and J. R. Moody

Inorganic Analytical Research Division

Center for Analytical Chemistry

- Instrumentation for Gases in Metals

The large part of this year was spent evaluating the commercial equipment that is presently available for the analysis of gases in metals. During the first half of the year, information was gathered and a trip was made by B. Diamondstone to the headquarters of the Leco corporation in St. Joseph, Michigan.

Requests were sent out for bids in the spring and the whole process was completed by July. The equipment was delivered and set up by mid August. The equipment received included: (1) a furnace and determinator for the measurement of carbon and sulfur in metals, (2) a furnace and determinator for the measurement of nitrogen and oxygen in metals, and (3) a furnace and determinator for the measurement of hydrogen in metals. Nearly all of the analyses performed to date on this new equipment have been for the determination of carbon and sulfur. Preliminary analyses have been made on the nitrogen/oxygen and hydrogen instruments mainly for the purpose of familiarizing the operators with the new instrumentation and obtaining gas dosing data on both instruments for calibration purposes.

It is anticipated that measurements on materials from a 1 ist to be generated by OSRM and Division 551 will begin early in FY83.

\section{- Nitrogen in Steel}

During the last quarter, work continued on this method but was hampered by equipment failures and slow procurements. Most of the required reagents have been received but a few, such as silicone antifoam reagents, have not yet arrived. Both the Kjeldahl distillation apparatus, the manual titration end point determinator, and the sample digestor have been set up, repaired as necessary, and tested. Satisfactory calibration and recovery curves have been prepared for varying quantities of total nitrogen. 
The distillation apparatus itself was found to be so old and fragile that after several repairs, a new unit was ordered and has arrived. Satisfactory progress has been made in all respects except for the bomb dissolution. These bombs have been purchased and the next phase will involve studies on the recovery of known materials following the dissolution of samples in the Teflon bombs. Difficulties are expected at this point and visits to laboratories performing routine nitrogen in steel analysis will not take place until some experience has been gained in handling the bombs. At that point, the laboratory visits should be of assistance in applying all acquired skills to actual sample ana 7 ys is.

\section{.7 Increased Sensitivity in NAA by Background Reduction}

R. L. Zeigler and J.R. Vogt

Inorganic Analytical Research Division

Center for Analytical Chemistry

The detection limits for many elements determined by neutron activation analysis (NAA), both instrumentally and radiochemically, are frequently determined by the background level of radiation produced by other radionuclides in the sample. This task was split into two subtasks to develop methods to further reduce the background level of radiation using instrumental and radiochemical techniques.

During the past year, a Compton suppression has been set up and evaluated. In this system, the sample is inside the NaI(TI) anti-Compton shield, rather than outside as in some other designs. Since there is no detection of scattered photons in the forward direction [to the rear of the Ge(Li) detector)], the suppression at lower spectral energies is not as good as in systems where the Ge $(L i)$ detector is surrounded more completely. However, the suppression factor in the Compton edge for CS-137 is still about 8, for the middle of the spectrum about 4-5, and at the backscatter peak about 3.5. Since the improvement in sensitivity follows roughly the square root of the background, the increases in sensitivity for these portions of the spectrum are approximately $2.8,2.1$, and 1.9 , respectively.

With the sample inside the NaI(Tl) shield, both coincident photopeaks and Compton events for radionuclides with cascading transitions are suppressed. This effect reduces the spectral background more than simple Compton suppression. There are both positive and negative effects from the suppression of coincident gamma-rays. The positive aspect is that the sensitivities of non-coincident gamma-rays are improved. This can be of benefit in matrices where coincident gamma-rays account for a substantial part of the activity, such as Sc-46 in environmental materials and $\mathrm{Na}-24$ in biological materials. The negative aspect is that the sensitivity and accuracy of radionuclides having coincident gamma-rays is reduced. There is particularly significant for 
longer lived radionuclides for which coincident gamma-rays are common.

Overall, the system does improve the sensitivity by activation analysis for radionuclides which do not have coincident gamma-rays or relatively short half-lives. It should be particularly appropriate for chromium, and investigations involving this element are in progress.

One problem frequently encountered in the simultaneous determination of $\mathrm{Ag}$, As, $\mathrm{Cr}$, Mo, Sb, and Se in biological material using the current radiochemical separation procedure, is the high level of background Bremsstrahlung radiation produced by the high-energy beta particle emitted by $32 \mathrm{p}$. The inorganic ion-exchanger HMD (hydrated manganese dioxide) used to retain the six elements of interest also retains most or all of the phosphorous present. Research was, therefore, directed at developing a new procedure which would reduce to levels of $32 p$ retained by the HMD without affecting the behavior of the elements of interest.

A number of different approaches were investigated including varying the acid strength and composition of the eluting and wash media, increasing the number of washes, addition of $p$ holdback carrier, use of various resin preconditioning techniques, as well as combinations of the above techniques. Unfortunately, most procedural changes which reduced the $32 p$ levels also affected the behavior of some or all of the elements of interest. However, a method was found that, with carefully controlled experimental parameters, reduced the $32 p$ levels by $80-90 \%$, and had on $1 y$ minimal effects on the other elements. Changes from the original procedure include: increasing the amount (volume) of resin from two to three $\mathrm{mL}$; decreasing the amount of $\mathrm{Ag}$, As, $\mathrm{Cr}$, Mo, Sb, and Se carriers from 100 to $25 \mathrm{\mu g}$, preconditioning the resin with one $15 \mathrm{~mL}$ wash using a solution which is $1 \mathrm{M}$ in both $\mathrm{HNO}_{3}$ and $\mathrm{H}_{3} \mathrm{PO}_{4}$ followed three or more $15 \mathrm{~mL}$ rinses with $1 \mathrm{M} \mathrm{HNO} 3$, and changing the two $15 \mathrm{~mL}$ post-elution washes from a solution which is $1 \mathrm{M}$ $\mathrm{HNO}_{3}$, to one which is $1 \mathrm{M} \mathrm{HNO}_{3}$ and $0.0025 \mathrm{M} \mathrm{H}_{3} \mathrm{PO}_{4}$. The volume of post wash solution used is critical since often about $40-50 \mathrm{~mL}$ passes through the column, large fractions of the Cr breaks through the resin. With this new procedure, Ag, As, Mo, and Sb were found to be quantitatively retained $(>99.5 \%)$ by the resin, and $\mathrm{Cr}$ and Se were nearly quantitative $(\geq 98.5 \%)$. The amount of $32 p$ retained by the resin from Bovine Liver (SRM 1577) was between 10-20\% of the amount originally present, and this resulted in a corresponding reduction of background around the 51 Cr peak ( $320 \mathrm{KeV})$ by a factor of 5-10. In addition, the behavior of $\mathrm{Cd}$ and $\mathrm{Cu}$, which are frequently determined in the combined eluted and wash solutions, were not affected $(>99.5 \%$ eluted), and could therefore still be determined following the new procedure for $\mathrm{Ag}, \mathrm{As}, \mathrm{Cr}, \mathrm{Mo}, \mathrm{Sb}$, and $\mathrm{Se}$. 
J. D. Fassett, E.A.J. Michiels, H. M. Kingston

and J. W. Gramlich

Inorganic Analytical Research Division

Center for Analytical Chemistry

- Cadmium

A procedure has been developed to determine cadmium at ultratrace levels in biological materials by isotope dilution mass spectrometry. This procedure combines the use of microchemistry with the requisite control of the analytical blank and high sensitivity pulse counting mass spectrometry with ionization enhancement. The procedure was used to determine cd in CDC bovine blood samples.

An extensive effort was made to identify and quantify all sources of chemical bank in the procedures, where the chemical blank arises from the dissolution and separation of the sample and mass spectrometric loading. The table below summarizes the sources of blank. An average "total system" blank of $103 \pm 53 \mathrm{pg}(N=5)$ was demonstrated which would allow a $5-10 \%$ uncertainty in Cd determinations of "normal" human blood with 0.3 to $0.6 \mathrm{ng} / \mathrm{g}$ of $\mathrm{cd}$. These total system blank measurements are suggestive that with further experience, control of the blank will be improved.

Determinations

Range

Reagent blanks

$\mathrm{HNO}_{3}$

$\mathrm{HC} 1$

$\mathrm{HC} 10_{4}$

$\mathrm{HBr}(A C S)$

HBr (cleaned)

Column Blank ( $1.5 \mathrm{~mL}$ resin)

The yields of several alternative chemical separation procedures using anion exchange chromatography were verified through tracer experiments on synthetic samples and real blood samples. A comparison of procedures using strongly basic anion resin in the bromide and chloride forms was made. The higher chemical blank of the bromide system discounted the increased efficiency of separation achieved. Thus, the selected procedure used the chloride form of the resin: a $1 \mathrm{~mL}$ column for the separation of $\mathrm{Cd}$ from all other elements and a second very small, $0.06 \mathrm{~mL}$, "clean-up" column. 
The mass spectrometric loading procedure utilized a single filament silica gel technique which provided significant ionization enhancement. This procedure entails drying sequential layers of silica gel, sample, and phosphoric acid and is critical in achieving good signal intensity. The mass spectrometric loading blank using this procedure was insignificant (2.6 pg). Both $114 \mathrm{Cd} / 111_{\mathrm{Cd}}$ and $112 \mathrm{~cd} / 111_{\mathrm{Cd}}$ ratios were measured which allowed internal normalization for isotopic fractionation to be made.

Four CDC bovine blood samples were analyzed. About two gram samples of blood were spiked with $111_{C d}$ and dissolved using wet ashing oxidation. The Cd was separated and mass spectrometrically analyzed. The cd concentration of these samples ranged from 7.01 to $7.09 \mathrm{ng} / \mathrm{g}$. The internal normalization procedure improved measurement precision by a factor of three ( 1.6 to $0.5 \%, 1$ sigma) and resulted in a $+5.0 \%$ correction due to isotopic fractionation. Blank corrections were typically $5 \%$.

The high sensitivity procedure developed should readily be adapted to the determination of $C d$ in a broad range of materials.

\section{- Vanadium}

Experiments were conducted to identify the sources of blank for both the chemical dissolution/separation procedures and the instrumental procedures. The analytical blank resulting from the chemistry is less than one nanogram. The primary source of the instrumental blank is not vanadium but an isobaric interference from the ${ }^{50} \mathrm{Cr}$ isotope emitted from the filament material. By washing the filaments in dilute hydrochloric acid, replacing the normal stainless steel post with tungsten rods, and heating in a vacuum at $2000{ }^{\circ} \mathrm{C}$ for one hour, the instrumental blank can approach the detection limits of the mass spectrometer. Having reduced the blank significantly, the concentration of vanadium was determined in SRM 1646, Estuarine Sediment and a Canadian standard in which there was some disagreement as to the true values.

Due to the low levels of vanadium in the matricies of interest, a new low level spike $(50 \mathrm{~V})$ was prepared at a considerably lower concentration level than previously investigated. This spike is stable for approximately one year. It has been calibrated by two different mass spectrometric procedures; one using a Faraday cage detection system and a second using pulse counting detection. The precision for values using both instruments was less than 0.5 percent.

It was necessary to investigate the separation efficiency for vanadium in biological and botanical matrices. Two separation procedures using strong acids were investigated. The most promising of the two procedures, using concentrated perchloric acid, utilizes some unique properties of vanadium to 
cause it to be quantitatively retained on a cation exchange resin. The column geometry was found to be critical. Under optimum conditions quantitative recoveries were obtained for both separation procedures tested.

At the present time, both 0yster Tissue (SRM 1566) and Citrus Leaves (SRM 1572) are being prepared for mass spectrometric analysis.

.9 Analysis of SRM 1649, Urban Dust/Organics, for the Determination of Polycyclic Aromatic Compounds

S. A. Wise, S. N. Chesler, L. R. Hilpert, W. E. May, and $C . R$. Vogt

Organic Analytical Research Division

Center for Analytical Chemistry

SRM 1649, Urban Dust/Organics, which became available in early 1982, has certified values for five polycyclic aromatic hydrocarbons (PAH) and information values for another nine PAH. With the availability of this large quantity (10-g units) of homogeneous air particulate material, we anticipate interest for PAH constituents in addition to those currently certified and eventually for other organic constituents. As a result of this interest, this SRM has been extensively characterized for the determination of major and minor PAH components. In addition, qualitative information on the polycyclic aromatic sulfur heterocycles (PASH) and polycyclic aromatic nitrogen heterocycles (PANH) has been obtained.

The extraction of air particulate matter with an organic solvent provides a complex mixture of organic constituents from which the PAH must be isolated prior to identification and quantitation. The PAH mixtures isolated from air particulate matter are also extremely complex because of the presence of numerous alkyl-substituted PAH as well as the numerous isomeric parent PAH. The complexity of these PAH mixtures necessitates the use of high resolution gas and/or liquid chromatographic (GC and $L C$ ) techniques with selective detection [e.g., fluorescence and mass spectrometry (MS)] to achieve separation, identification, and quantitation of the individual components. We have used three chromatographic approaches to characterize the PAH mixture from SRM 1649: (1) capillary GC, (2) LC with selective fluorescence detection, and (3) multidimensional chromatographic techniques ( $i . e$., normal-phase LC to isolate specific PAH

fractions followed by GC, GC/MS, and/or reversed-phase LC). The first two approaches were used for the certification of selected major PAH components in SRM 1649. The third approach has been utilized to provide a detailed characterization of both the major and minor PAH components in SRM 1649. 
After isolating the PAH fraction from the air particulate extract, the PAH mixture was fractionated using normal-phase LC on an aminosilane column as shown in figure 1. The individual fractions were then analyzed by GC/MS and reversed-phase LC for identification and quantitation of individual compounds. The gas chromatograms from the analyses of fractions 5 and 7 (see figure 1) are shown in figures 2 and 3 . These chromatograms illustrate the complexity of the PAH mixture even after fractionation into groups of isomers. Without preseparation by normal-phase LC into the various fractions, it would be difficult to identify and quantify the numerous minor components in the mixture. Quantitation of the individual components was based on using the PAH for which certified and information values were available as internal standards in the various fractions. Table 1 contains a brief summary of the numerous parent PAH and PASH and alkyl-substituted PAH which have been identified in SRM 1649. In addition to the PAH, the major PANH were identified as quinoline, isoquinoline, and alkyl-substituted quinolines/isoquinolines.

In the development of methods for the determination of PASH, research has focused on investigation of the LC retention characteristics of PASH. Reversed-phase and normal-phase LC retention data have been obtained for approximately 50 parent and methyl-substituted PASH. In normal-phase LC the PASH have elution characteristics similar to the PAH, i.e., they elute according to the number of aromatic carbon atoms. Reversed-phase LC has been found to have excellent selectivity for the separation of PASH isomers. Studies indicate that the reversed-phase LC separations of PASH are influenced by the shape of the solute as was previously found for PAH.

\section{. 10 Methods for the Determination of Vitamins in Milk}

J. M. Brown-Thomas, S. A. Margolis, L. Watts,

R. B. Weker

Organic Analytical Research Division

Center for Analytical Chemistry

The primary objective of this program is to develop new methods and to apply established methods for the accurate measurement of organic nutrients, including vitamins, in food materials. Specifically, we expect to initially provide reference or certified values for organic nutrients in a proposed nonfat, dry milk SRM. During FY81 we examined methods for the measurement of Vitamin D, lactose, and nicotinic acid. During the past year, we have improved the extraction methods for nicotinic acid and completed our work on Vitamin D and lactose. During FY83 we anticipate completing our SRM measurements on nicotinic acid and beginning work on thiamin, lactic acid, and pyridoxine. 


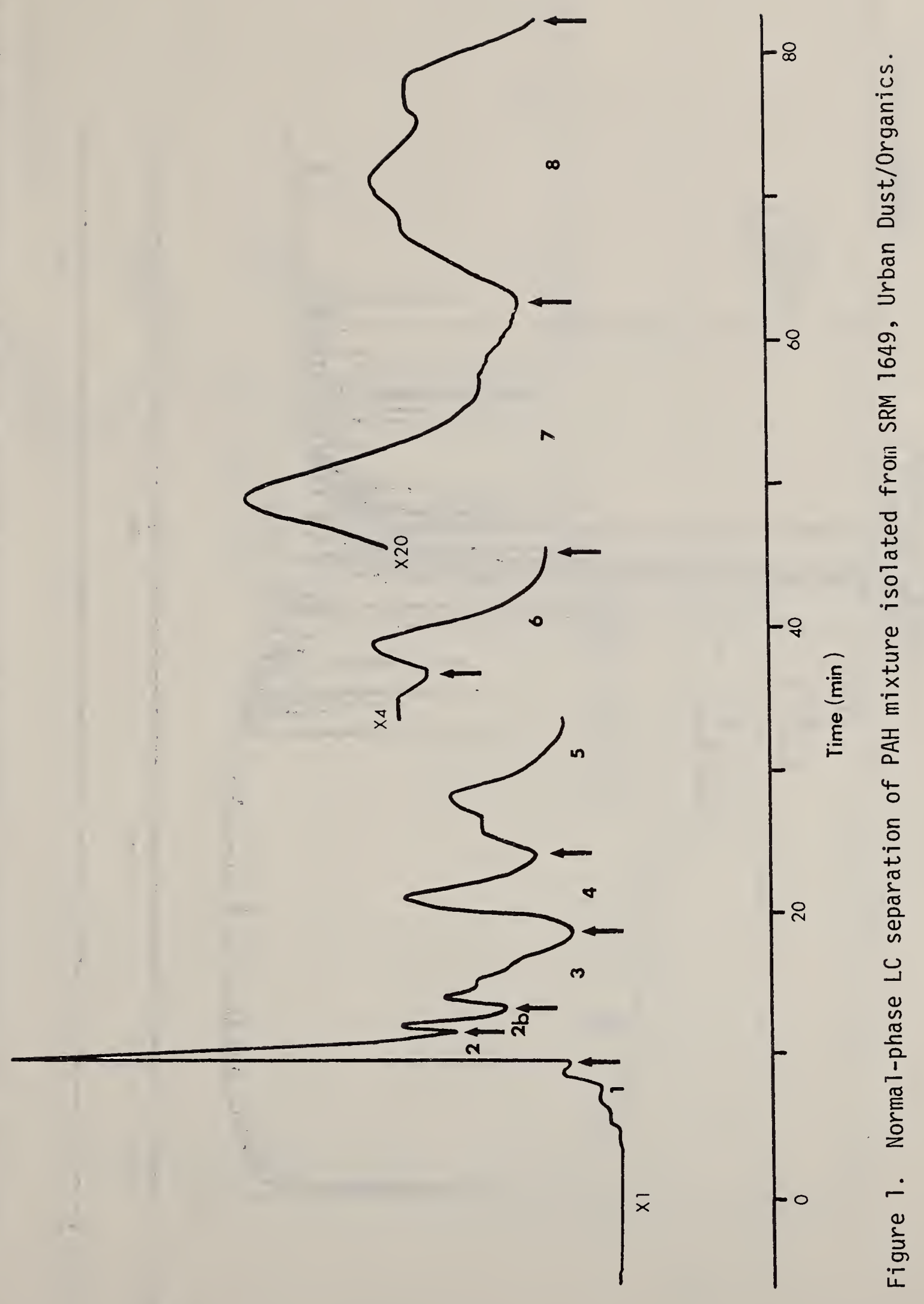




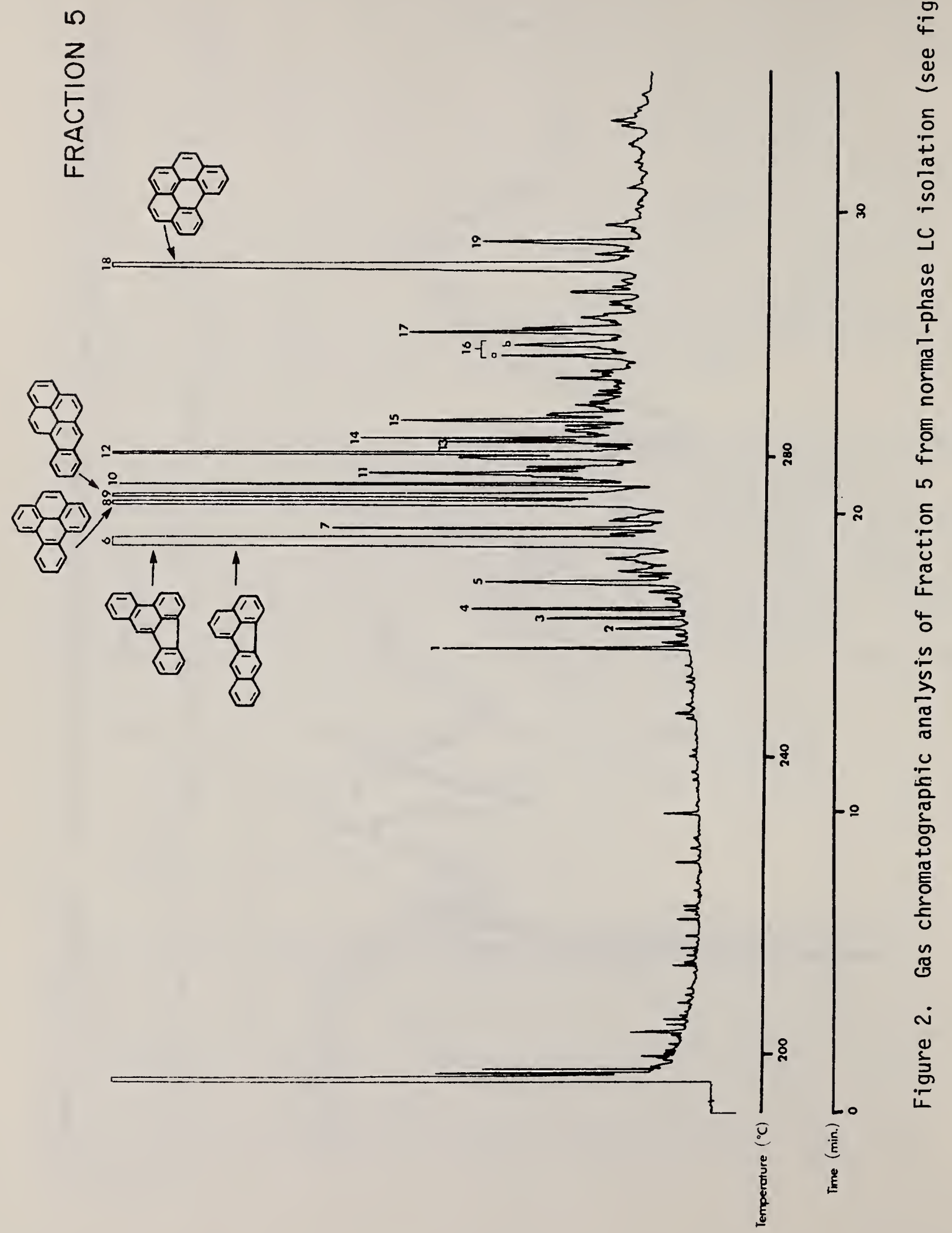




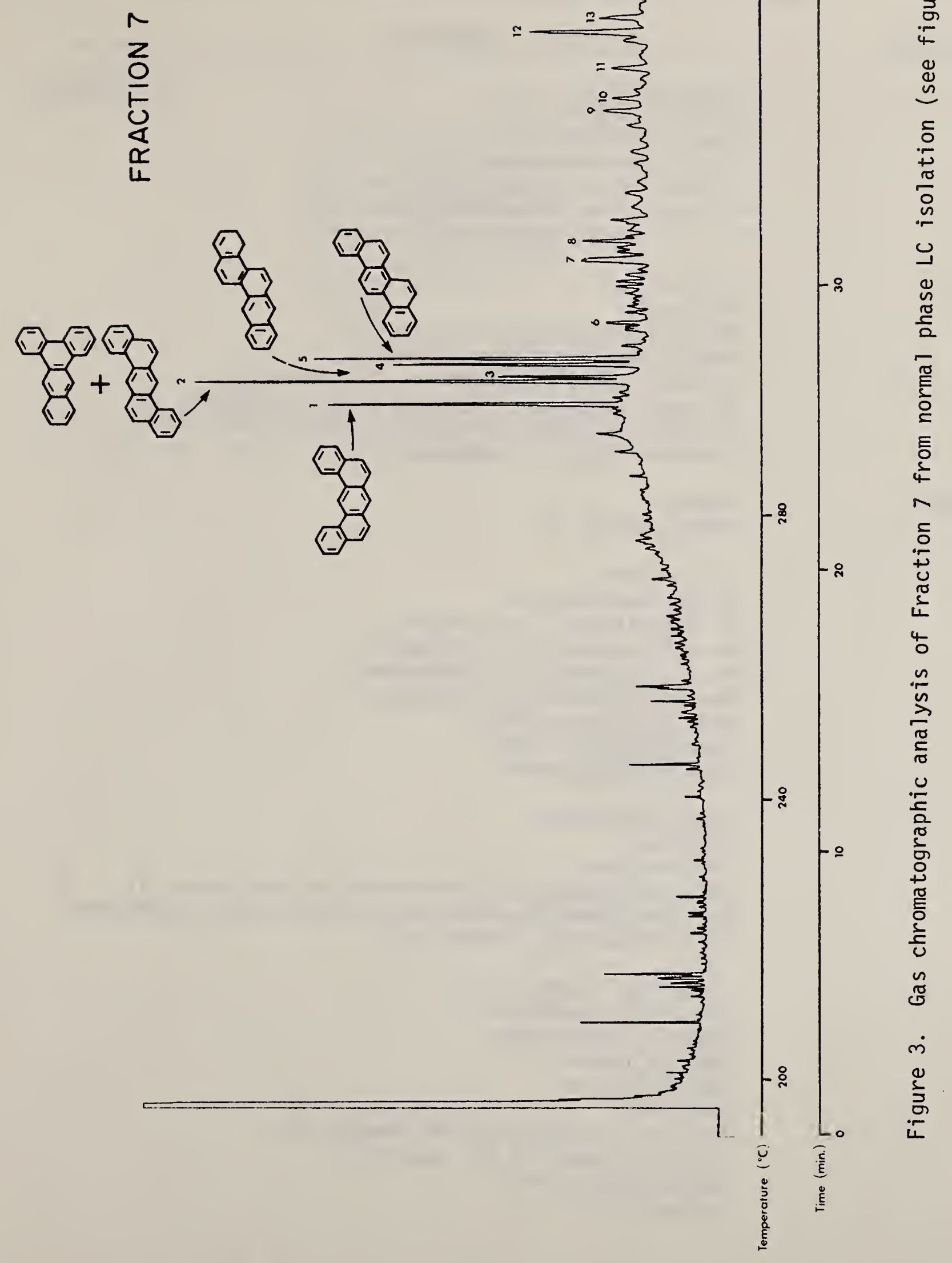


Table 1. Polycyclic Aromatic Compounds Identified in Washington Urban Particulate Material (SRM 1649)

Fraction No.

1

2

$2 b$

3

4
Compound

Fluorene

Methylfluorenes (2) ${ }^{\mathrm{a}}$

*Dibenzothiophene

Methyldibenzothiophenes (3)

${ }^{*} \mathrm{C}_{2}$-substituted dibenzothiophenes

${ }^{*} \mathrm{C}_{3}$-substituted dibenzothiophenes

${ }^{*} \mathrm{C}_{4}$-substituted dibenzothiophenes

Phenanthrene

Anthracene

Methylphenanthrene/anthracenes (4)

$4 \mathrm{H}$-Cyclopenta[def] phenanthrene

$\mathrm{C}_{2}$-substituted phenanthrene/anthracenes (9)

$\mathrm{C}_{2}$-substituted $4 \mathrm{H}$-cyclopenta[def]phenanthrenes (3)

$\mathrm{C}_{3}$-substituted $4 \mathrm{H}$-cyclopenta[def] phenanthrenes (3)

*Phenanthro $[\underline{4}, \underline{5-b c d}]$ thiophene

Pyrene

Methylpyrenes

(2)

Fluoranthene

Methylfluoranthenes

$\mathrm{C}_{2}$-substituted fluoranthenes

*Benzo[b]naphtho[2,1-d] thiophene

*Benzo [b] naphtho[T,,$\overline{2}$-d] thiophene

*Benzo[b]naphtho $[\underline{2}, \overline{3}-\bar{d}]$ thiophene

Benzo[ghi]fluoranthene

Benzo[c] c ]phenanthrene

Cyclopenta[cd]pyrene

Benz[a]anthracene

Chrysene

Triphenylene

Methylchrysene/benz [a] anthracene/triphenylenes (4)

$\mathrm{C}_{2}$-substituted chrysene/benz [a] anthracene/triphenylenes

Methylbinaphthyl isomers (4)

Binaphthyl isomers (3)

Benzo[b]fluoranthene

Benzo[k] fluoranthene

Benzo[e]pyrene

Benzo[a] pyrene

Perylene

Methyl-substituted 252 MW isomers (3)

$\mathrm{C}_{2}$-substituted $252 \mathrm{MW}$ isomers (2)

Benzo[ghi]perylene

Anthanthrene 
Table 1. (Continued)

Fraction No.

Compound

6

Indeno $[1,2,3$-cd $]$ fluoranthene

Indeno $[\underline{1}, \underline{2}, \underline{3}-\underline{\underline{c}}]$ pyrene

7

Dibenz $[a, j]$ anthracene

Dibenz $[\bar{a}, \bar{c}]$ anthracene

Dibenz $[\bar{a}, \bar{h}]$ anthracene

Benzo[b] chrysene

Picene

8

Dibenzopyrene isomers (6)

* Sulfur containing polycyclic aromatic compounds.

a $($ ) indicates number of isomers present. 
The accepted methods for the extraction of nicotinic acid from food matrices, such as autoclaving in strong acid or base, are harsh and lead to the formation of many undesirable products. Therefore, we have developed a milder extraction procedure using sulfosalacylic acid (SSA) as a protein precipitant in the presence of hydrochloric acid. This procedure allows the quantitative extraction of added nicotinic acid from milk samples. However, the use of this extraction method requires the modification of the analytical procedure to remove the highly UV-absorbing SSA before nicotinic acid analysis. This was achieved by using multidimensional chromatographic analysis. The sample was applied to an octadecylsilane (ODS) reversed-phase column which preferentially retained the SSA. The nicotinic acid was subsequently adsorbed onto an aminosilane column (connected in series to the ODS column) and eluted with a phosphate buffer gradient. This method allows the quantitation of nicotinic acid in milk samples which have been supplemented with $62 \mu \mathrm{g}$ of nicotinic acid per gram of milk powder (containing $10 \mu \mathrm{g}$ of native nicotinic acid by microbiological assay). The research to complete development of this assay procedure will include the refinement of the chromatographic process and development of a process for weak basic hydrolysis of the covalently bonded nicotinamide and its conversion to nicotinic acid.

The method developed for the analysis of Vitamin D involved the use of enzymatic ( 1 ipase) hydrolysis, HPLC separation of Vitamins $D_{2}$ and $D_{3}$ from the milk matrix with $V i t a m i n D_{3}$ as the internal standard, and a sequential HPLC procedure for final separation and quantitation. The lipase hydroyzate was

fractionated on a cyanopropylsilane (CN) column using a 2 percent isopropyl alcohol/hexane mobile phase. Fractionation of a milk extract on a CN column is illustrated in figure 4. The lipase hydrolyzate fraction is between the dashed lines. Vitamin $D_{2}$ was separated from $V$ itamin $D_{3}$ and other co-extracted components by chromatography of the vitamin D-containing fraction by an acetonitrile mobile phase (figure 5). The D vitamins were measured by UV detection at $267 \mathrm{~nm}$. The results of the analysis of Vitamin $D_{2}$ in a commercial milk formulation and in the SRM candidate dry milk material are summarized in Table 2.

The lactose content of the SRM candidate dry milk material was measured by HPLC utilizing a carbohydrate column. The lactose was eluted with 80 percent acetonitrile/water and measured with a refraction index detector (figure 6). By use of an external standard, the lactose content was found to be $44 \pm 1$ percent $(\mathrm{g} / \mathrm{g})$ in the candidate SRM and $34 \pm 1$ percent $(\mathrm{g} / \mathrm{g})$ in a commercial milk sample. 


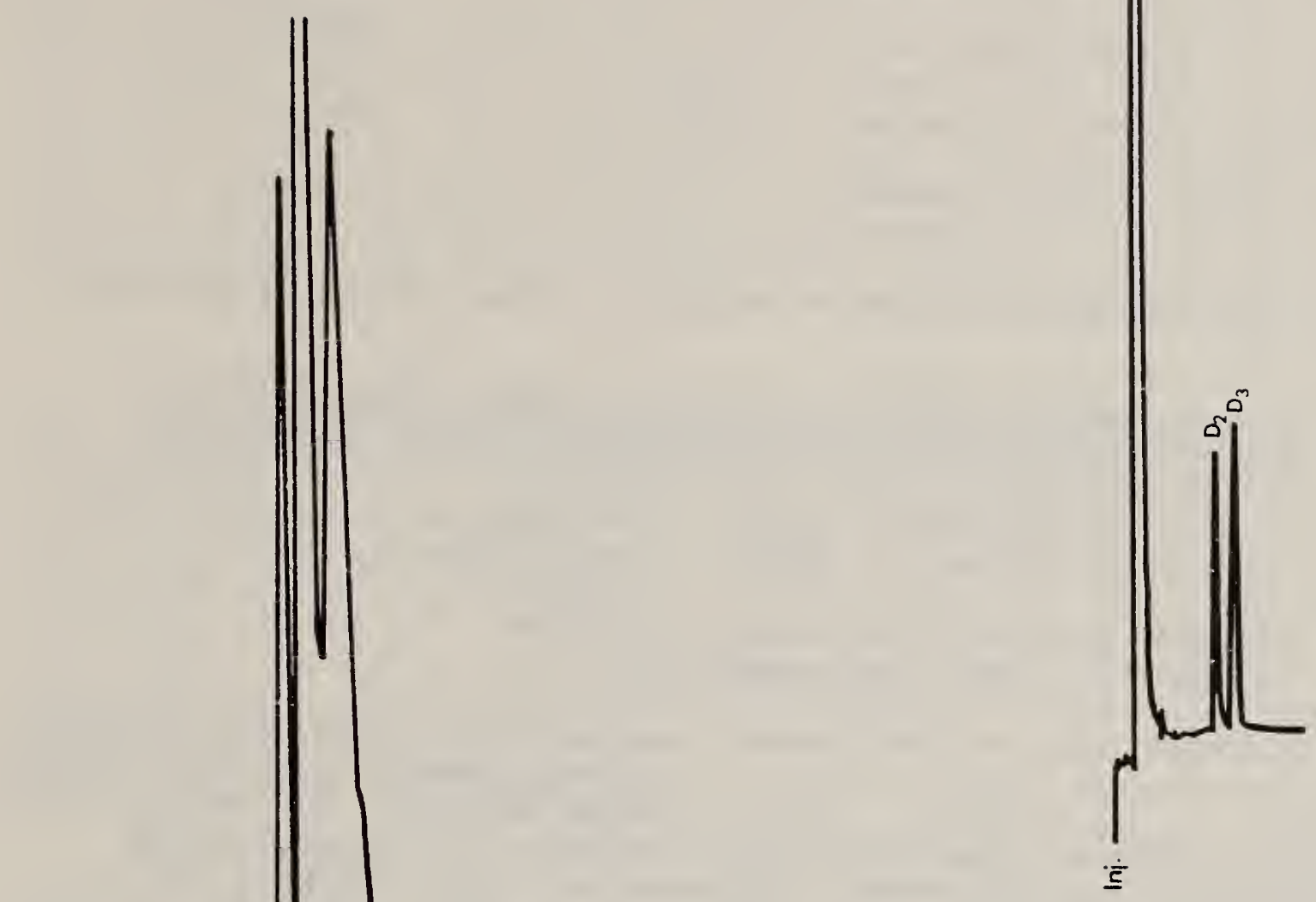

Figure 5. Analysis of a milk fraction for Vitamin $D_{2}$ on a reversed-phase column.

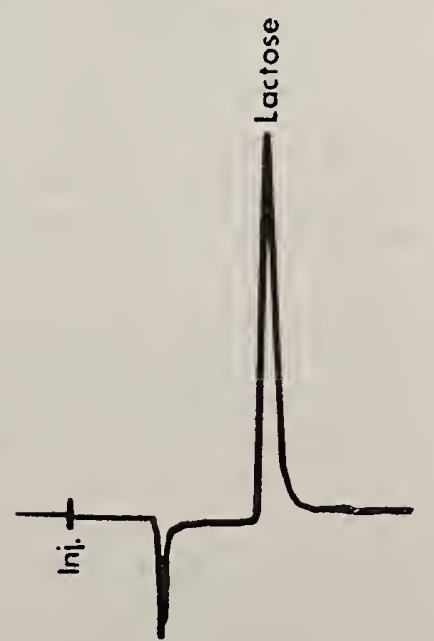

Figure 6 . Analysis of lactose in a milk sample on a reversed-phase column. 
Table 2. Concentration of Vitamin $D_{2}$ in Dry Milk

Sample

Commercial Fortified Material-Box 1

Commercial Fortified Material-Box 2

Commercial Fortified Material-Box 3

Unfortified SRM candidate
$\underline{D_{2}}(\mathrm{ng} / \mathrm{g} \mathrm{milk} \pm \mathrm{SD})$

$83 \pm 3^{a}$

$70 \pm 3$

95

$<10$

a values represent standard deviation of a single measurement.

.11 Development of an Isotope Dilution/Mass Spectrometric Definitive Method for the Determination of Serum Urea

A. Cohen, H. S. Hertz, R. Schaffer, L. T. Sniegoski, M. J. Welch, E. White, V, W. T. Yap

Organic Analytical Research Division

Center for Analytical Chemistry

Definitive methods provide the clinical chemistry community with an accuracy base to which reference, and ultimately, field methods can be compared. We have been involved for several years in the development of definitive methods for organic serum analytes and have successfully developed such methods for cholesterol, glucose, and uric acid. Another clinically important analyte in serum urea, which is used as a measure of kidney function and in protein metabolism studies. Work has now been completed on a method for serum urea which is of sufficient accuracy and precision to be considered a definitive method.

This method utilizes isotope dilution mass spectrometry, as have all of the other definitive methods for organic serum analytes. A brief description of the method is as follows: A weighed quantity of urea-180 is added to a known weight of serum such that the labeled/unlabeled urea ratio is near $1: 1$. After an equilibration period, the sample is freeze-dried and the urea is extracted from the residue and sublimed. The sublimate is added to a mixture of diketene and glacial acetic acid in a vial, which is then sealed and heated at $82-82{ }^{\circ} \mathrm{C}$ for two days. Under these conditions urea is converted in high yield to 6-methyluracil. After the solvent and unreacted diketene are evaporated, bis(trimethylsilyl)acetamide is added to convert the product to 6-methyluracil-diTMS. Calibration standards, consisting of known amounts of the labeled urea-180 and pure Standard Reference Material (SRM) 912, Urea, are also converted to the derivative. For each sample, the two standards, whose unlabeled/labeled 
weight ratios most closely bracket that of the sample, are selected. The sample and its two standards are injected onto a 30 -meter SE-30 SCOT gas chromatographic column operated at $125{ }^{\circ} \mathrm{C}$ in the following sequence: One standard is injected, followed 5-1/2 minutes later by the sample and 11 minutes later by the other standard. After a 25 minute retention time, the ion abundance ratios for the $(M-15)^{+}$ions at $\mathrm{m} / \mathrm{z} 255$ (unlabeled) and 257 (1abeled) are measured for each of the three peaks.

Measurements are made in the electron impact (EI) mode at 70 eV, utilizing magnetic field switching. The ratio from the sample is compared, using linear interpolation, with the ion abundance ratios from the standards to find the quantity of unlabeled urea in the sample. For each sample, measurements are reported, on a second day with the order of standards reversed, and the mean of the two days' measurements is taken as the reported result.

Because of contributions of the labeled urea derivative at the mass monitored for the unlabeled derivative, and vice versa, the relationship between weight ratios and ion abundance ratios is not truly linear. A mathematical study was performed to find the maximum error possible when linear interpolation was used with our bracketing standards. The worst case, which occurs when the ratios of the two standards are the farthest apart and the bracketed sample falls midway between the two, was found to be less than 0.04 percent for our standards. Thus, linear interpolation can be used without correction. A description of this mathematical study has been submitted for publication in Biomedical Mass Spectrometry.

The method was used to measure urea levels in both freeze-dried and frozen serum pools. Three sets of samples were prepared from SRM 909, a freeze-dried human serum pool. Each set consisted of two samples from each of three vials of SRM 909. The results are summarized in Table 3, including the overall mean value which is the certified concentration for the SRM. As a test for hidden interferences in the above measurement conditions, two samples from each set were remeasured using different pairs of ions; first, EI measurements of the $(M-30)^{++}$ ions at $\mathrm{m} / \mathrm{z} 120$ and 121 , and second, chemical ionization (CI) measurements of the $(M+1)^{+}$ions at $\mathrm{m} / \mathrm{z} 271$ and 273 . These results, along with the previous results for those six samples, are shown in Table 4 .

The urea level was also measured in five frozen serum pools from a Centers for Disease Control round robin study. Three sets, each consisting of one sample per pool, were independently prepared. The results are shown in Table 5 .

One sample from each pool was remeasured using the alternate ions. The mean differences from the results for the $255 / 257$ ions were +0.03 percent for the $120 / 121$ ions nad +0.01 percent for the $271 / 273$ ions. These pools were also analyzed at CDC by the coupled-enzyme candidate reference method. Their results for the five pools differed from our results by -0.58 percent to +1.15 
percent, differences which are small compared with the imprecision of their measurements, thus providing strong evidence that no serious systematic bias exists between the two methods.

For a method to be considered definitive, the results must be free of significant bias and be of high precision. This ID/MS method for urea has provided high precision results for both freeze-dried and frozen serum. Confirmatory measurements at alternate ions demonstrate that no significant biases exist among the three measurement conditions. Thus, the probability of a hidden interference is very small, since such an interference, to remain undetected, would have to co-elute with the 6-methyluracil-diTMS and contribute proportionally the same at the three ions measured. No other source of significant bias has been found, therefore, the requirements for a definitive method have been satisfied. A manuscript describing the method is in preparation.

Development of definitive methods for creatinine and triglycerides is in progress and a method for digoxin is in the planning stage. Each method developed will be used to certify the concentration of the corresponding analyte in the Human Serum SRM. 
Table 3. Urea Levels Found in the Human Serum SRM by the ID/MS Definitive Method ( 6 sample per set)

$\begin{array}{lll}\text { Set } & \text { mg urea/g serum pellets } & \\ 1 & 7.236 & \frac{C V}{\%} \\ 2 & 7.249 & 0.07 \\ 3 & 7.247 & 0.17 \\ & & 0.06\end{array}$

Statistical Summary: Mean $=7.244$; CV's - replicates $0.14 \%$, sets $0.10 \%$, reproducibility $0.17 \%$. Standard error of average $=.00439, C V=0.06 \%$.

Table 4. Urea Levels Found in Six Human Serum SRM Samples Using Three Different Pairs of Ions

\begin{tabular}{|c|c|c|c|}
\hline Is Meas & $\begin{array}{ll} & \text { Mean } \\
\text { mg urea/g } & \text { serum pellets }\end{array}$ & $\begin{array}{l}\mathrm{CV} \\
\% \\
\end{array}$ & $\begin{array}{l}\text { \% Difference from } \\
(255 / 257) \text { Results }\end{array}$ \\
\hline $\begin{array}{l}255 / 257 \\
120 / 121 \\
271 / 273\end{array}$ & $\begin{array}{l}7.242 \\
7.239 \\
7.240\end{array}$ & $\begin{array}{l}0.12 \\
0.12 \\
0.12\end{array}$ & $\begin{array}{l}-0.05 \\
-0.03\end{array}$ \\
\hline
\end{tabular}

Table 5. Urea Levels Found in Five Round Robin Frozen Serum Pools by the ID/MS Definitive Method

$\underline{P 001}$

Control 1

Control 2

Unknown 7

Unknown 8

Unknown 9
Mean

mg urea/g serum

.2393

.8828

1.525

.3564

.8259
CV

$\%$

0.13

0.14

0.23

0.13

0.15 
.12 Improved Instrumentation for Organic Isotope Dilution/Mass Spectrometry Measurements

S. Meiselman, F. Ruegg, R. Shideler, M. J. Welch, and E. White, V

Organic Research Analytical Division

Center for Analytical Chemistry

Our ongoing project to develop definitive methods for organic serum analytes requires instrumentation of high stability to provide the necessary precision. All of our work to date has been with serum analytes present in relatively high concentrations. As future work turns to analytes in lower concentration, our instrumentation must be even more stable than before, if we are to continue successful development of definitive methods. our approach to improved instrument stability has been to seek to upgrade existing instrumentation, rather than to purchase costly, new systems. In recent years, upgrades have included replacement of the mass spectrometer source diffusion pump with a turbomolecular pump for reduction of pressure fluctuations, installation of a pressure regulated flow system in the gas chromatograph, installation of a variable splitter at the head of GC column, and the use of fused silica tubing for the transfer line in the GC/MS interface.

Recently, we have replaced both the multiple ion monitoring system and our old data handling system with a new system assembled principally from components available in the NBS storeroom. The new system, diagrammed in figure 7 , is designed to provide computer control for certain instrument parameters which have to be rapidly and reproducibly changed, as well as to handle data acquisition and reduction. A $64 \mathrm{~K}$ microcomputer controls switching of the magnetic field for each measurement cycle, through a 16 bit digital-analog converter (DAC). After each switch of the magnetic field, the computer waits for a signal indicating that the field has stabilized before generating a triangular waveform through a \pm 150 volt power supply. This waveform, whose frequency and amplitude are computer controlled, is sent to the mass spectrometer detector beam deflection plates a preset integral number of times for each measurement cycle. This provides for more reproducible data acquisition than achieved with the old system in which the waveform was generated continuously and the measurement began at random points across the waveform. The ion intensity signal generated by the electron multiplier is fed through a solid state preamplifier, built at NBS, which provides better stability and linearity of response than the vacuum tube device which came with the mass spectrometer. The signal, after passing through the original amplifier for the mass spectrometer, is digitized by an analog-digital convertor $(A D C)$. The computer generates two real-time displays of the data; numerical data is shown on a CRT, and an analog signal is 


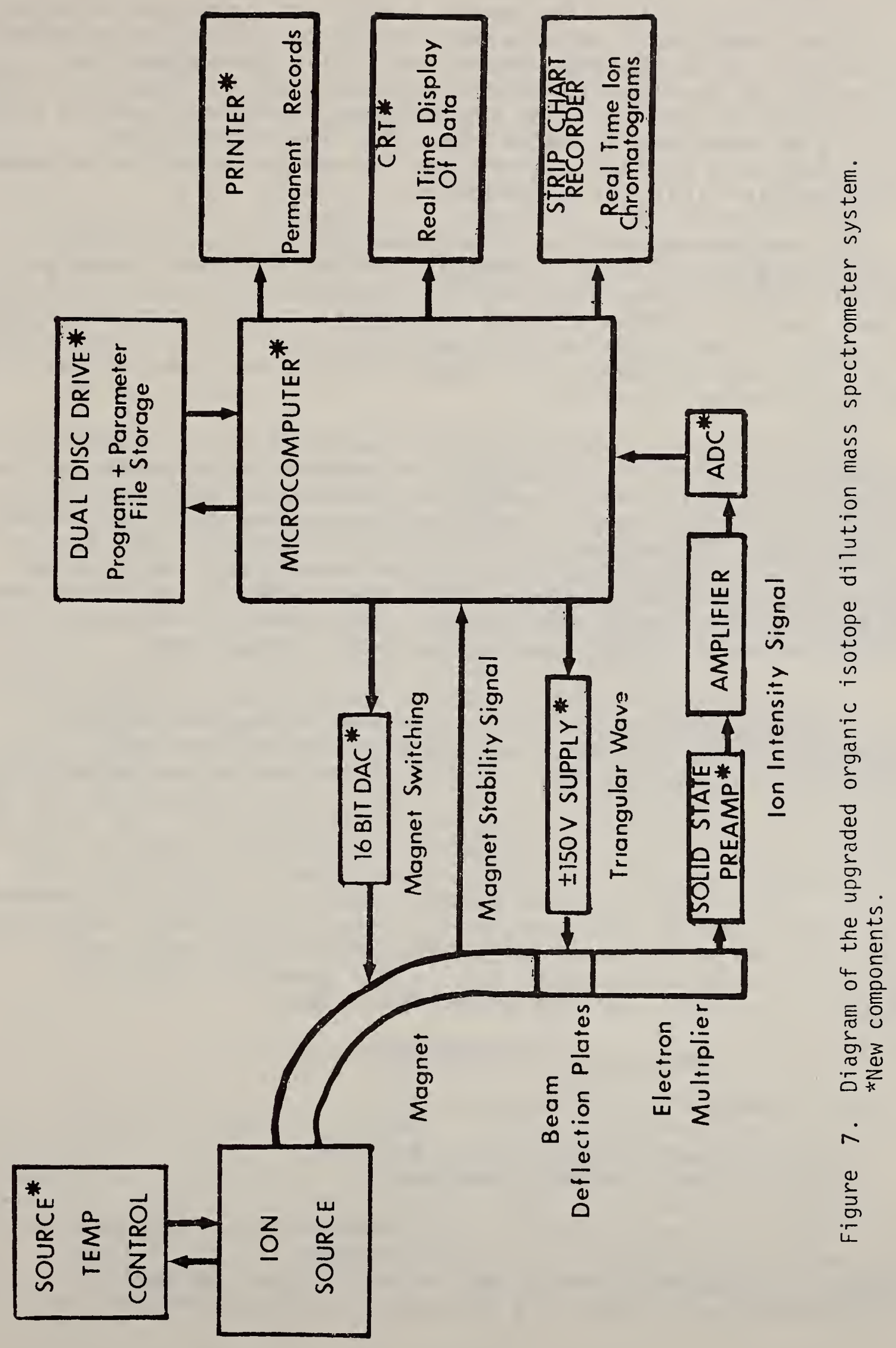


sent to a strip chart recorder for display of the ion chromatograms for the unlabeled and labeled species. After data acquisition is complete for each sample, the computer corrects the accumulated data for baselines measured before the elution of the analyte and calculates the ratio of the corrected ion abundances of the labeled and unlabeled species. The ratios are displayed on the CRT and the accumulated counts and ratios are fed to a printer for permanent record. The computer is interfaced to a dual disc drive for access to operating programs, and parameter files for each analyte.

The new system exhibits improved precision and greater reliability, enabling us to measure serum urea levels with an overall relative precision of 0.17 percent, compared with $0.2-0.4$ percent overall precisions for cholesterol and glucose with the old system. The computer provides the capability of controlling other instrumental parameters and modifying our data acquisition and reduction as necessary.

Our most recent system upgrade has been installation of an NBS-built circuit to control the ion source temperature in the mass spectrometer. Previously, the ion source temperature changed while measurements were being made and corrections were through manual adjustments in the heater current. The new circuit senses the temperature in the source and adjusts the heater current appropriately. This improvement simplifies the operator's task and we also expect it to make ion source conditions more stable, leading to better precision.

Plans for further improvements include acquisition of an electron-impact-only ion source for the instrument to use in conjunction with our combined electron-impact chemical-

ionization source. Such a source, optimized for one mode of ionization, is expected to provide more stable operation in that mode than is possible with the combination source. We also plan to test a new ion selection method in which the magnetic field is held constant and the ion beam is switched at the deflection plates. Such a system should allow for less delay time between measurement cycles since magnetic hysteresis effects, which now limit the switching rate, will be avoided. The major effort required for this new technique is the generation of the necessary software for the existing system.

\section{.13 Suríace Reactions of Gas Mixtures}

\section{Walter L. Zielinski}

Gas and Particulate Science Division

Center for Analytical Chemistry

One of the most perplexing, time-consuming, and costry phenomenon encountered in the development of gas cylinder mixtures for SRM certification is that of gas instability. This is observed analytically by decreases in the concentration of the 
certifiable gas specie over a period of time. Instability is most often encountered in cylinders containing reactive gas species ( $\mathrm{NO}_{0} \mathrm{NO}_{2} \mathrm{SO}_{2}, \mathrm{CO}$ ), and is believed to be primarily due to reactions occurring at the surface of cylinder walls and valves. Such reactions may be catalyzed by metal oxides, traces of water, hydrocarbons, and trace gas impurities. The objective of this research is to characterize the chemical nature of unstable gas mixtures in order that gas standards instability may be better understood, and minimized or eliminated. The research approach taken is aimed at the identification and measurement of the differences in principal and trace gas phase constituents between stable and unstable gas cylinder mixtures, as well as assessing species adsorbed by the cylinder wall surface.

(1) Gas Phas Studies of $\mathrm{NO}_{\mathrm{i}} \mathrm{N}_{2}$ Cylinder Mixtures (B. C. Cadoff)

Decreases in the concentration of $\mathrm{N}_{0}$ in $\mathrm{N}_{2}$ gas cylinder mixtures with time have occasionally been noted, resulting in the rejection of such cylinders as SRM's. The decrease in NO over a several month period can be as high as $2 \%$ or more, the explicit cause of which is unknown. An analytical investigation was undertaken of stable and unstable $\mathrm{NO}_{0}$ in $\mathrm{N}_{2}$ cylinders taken from three cylinder batches (nominal concentrations: 100, 500 and $1000 \mathrm{ppm})$. While it was recognized that these cylinders were prepared commercially, it was felt that they would represent a useful preliminary model for analytical studies.

In order to ascertain trace gas species which were potentially relevant to observed NO concentration decreases, homogeneous gas phase reactions were considered that could occur in the cylinder:

$$
\begin{gathered}
2 \mathrm{NO}_{2}+\mathrm{O}_{2} \longrightarrow 2 \mathrm{NO}_{2} \\
2 \mathrm{NO}_{2} \leftrightharpoons \mathrm{N}_{2} \mathrm{O}_{4} \\
\mathrm{NO}+\mathrm{NO}_{2} \leftrightharpoons \mathrm{N}_{2} \mathrm{O}_{3} \\
3 \mathrm{NO}_{2}+\mathrm{H}_{2} \mathrm{O} \leftrightharpoons 2 \mathrm{HNO}_{3}+\mathrm{NO} \\
\mathrm{NO}+\mathrm{NO}_{2}+\mathrm{H}_{2} \mathrm{O} \leftrightharpoons 2 \mathrm{HNO}_{2}
\end{gathered}
$$

Equilibrium and rate constants are either known or can be calculated for these reactions. These constants were used in a CCP kinetics computer program that yields concentrations of products as a function of time for selected starting concentrations of $\mathrm{NO}_{0} \mathrm{NO}_{2}, \mathrm{O}_{2}$ and $\mathrm{H}_{2} \mathrm{O}$. Preliminary modeling for the $100 \mathrm{ppm}$ NO case verified that:

- oxygen, if present initially, would be rapidly consumed (several hours) due to the rapid rate of reaction (1). 
- The only significant reactions resulting in loss of NO are reactions (1) and (5).

- Time-scale changes in NO concentration are in the order of several months to a few years, depending on the initial concentration of the other species present $\left(\mathrm{H}_{2} \mathrm{O}, \mathrm{O}_{2}, \mathrm{NO}_{2}\right)$.

One important observation of the modeling was that $\mathrm{HNO}_{2}$ is produced as a principal end-product of NO gas phase chemistry (reaction (5)). Excluding significant cylinder wall surface effects, analysis of $\mathrm{HNO}_{2}$ might infer whether or not, and to what extent, the reactions in the cylinder are homogeneous gas phase.

Preliminary analyses to ascertain the presence of $\mathrm{HNO}_{2}$, run using Fourier-transform IR spectroscopy (FTIR) using a $20 \mathrm{~cm}$ IR cell, were inconclusive. A long-path "white" cell (effective pathlength, $110 \mathrm{~m}$ ) is now being put into service, which should provide the required sensitivity for this analysis. This cell will be used to assess the presence of other products (e.g., $\mathrm{NO}_{2}$ ) and trace impurities. Direct inlet high-resolution mass spectrometry revealed a higher m/e 52 line in unstable No mixtures. Preliminary data indicated the species as cyanogen; this will be reexamined using the FTIR white cell.

Reaction (5) also pointed out the need for accurate and precise analytical methods for trace $\mathrm{NO}_{2}$ and $\mathrm{H}_{2}$. Table 6 presents data for $\mathrm{H}_{2} \mathrm{O}$ and $\mathrm{NO}$ concentrations for six cylinders. Data collection of trace species has been underway and will continue over the next several months. Sufficient data are needed before meaningful conclusions can be drawn regarding NO stability. Improved methodology for trace levels of $\mathrm{NO}_{2}$ and $\mathrm{H}_{2} \mathrm{O}$ in the presence of $N O$ is currently being evaluated.

Future investigations should consider analytical studies of the chemistry of $\mathrm{NO}_{\text {in }} \mathrm{N}_{2}$ mixtures in which we condition and fill cylinders with known starting materials and analyze the relevant trace species over time. Such experiments should yield an improved control of the experimental design and allow further examination of cylinder surface effects on gas instability. 
Table 6. Analytical Data for Selected NO Cylinders

Cylinder Identification

Nominal No Conc (ppm)

Analyzed NO Conc. Analyzed $\mathrm{H}_{2} \mathrm{O}$ Conc (ppm)

\begin{tabular}{|c|c|c|c|c|}
\hline $41-4-C$ & 1000 & $\begin{array}{l}955 \\
920\end{array}$ & $\begin{array}{l}(2 / 80) \\
(12 / 81)\end{array}$ & $12.0(9 / 82)$ \\
\hline $41-2-C$ & 1000 & $\begin{array}{l}955 \\
955\end{array}$ & $\begin{array}{l}(2 / 80) \\
(12 / 81)\end{array}$ & $6.1(9 / 82)$ \\
\hline $42-32-C$ & 500 & $\begin{array}{l}472 \\
454\end{array}$ & $\begin{array}{l}(12 / 80) \\
(8 / 81)\end{array}$ & $8.3(9 / 82)$ \\
\hline $42-15-G$ & 500 & $\begin{array}{l}471 \\
471\end{array}$ & $\begin{array}{l}(12 / 80) \\
(8 / 81)\end{array}$ & $10.5(9.82)$ \\
\hline $44-68-G$ & 100 & $\begin{array}{l}93.1 \\
92.6\end{array}$ & $\begin{array}{l}(5 / 81) \\
(11 / 81)\end{array}$ & $30.0(9 / 82)$ \\
\hline $44-98-G$ & 100 & $\begin{array}{l}93.1 \\
93.1\end{array}$ & $\begin{array}{l}(5 / 81) \\
(11 / 81)\end{array}$ & $16.5(9 / 82)$ \\
\hline
\end{tabular}


(2) Surface Absorption of Trace Water in $\mathrm{SO}_{2}$ in $\mathrm{N}_{2}$ Cylinder Mixtures (G. Sleater)

Several cylinders having $\mathrm{SO}_{2}$ concentrations significantly lower than the batch average were selected from batches of $\mathrm{SO}_{2}$ in $\mathrm{N}_{2}$. It was proposed that the level of moisture in the cylinders might influence loss of $\mathrm{SO}_{2}$. Consequently, water vapor content of these cylinders was studied as a function of cylinder pressure and cylinder temperature.

Initial water analysis (coulometric trace moisture analyzer) revealed that cylinders that were lowest in $\mathrm{SO}_{2}$ contained about twice the water level (50-100 ppm) compared to cylinders having an $\mathrm{SO}_{2}$ concentration similar to that of the batch standards. As the cylinder pressure was progressively decreased from an initial pressure of 1500 psi or more, to below 200 psi, the water content showed an initial marked increase followed by a rapid decrease. Water levels decreased as the cylinder pressure was lowered to about 500 psi, following which, a slight increase in water was noted. The increases in water concentration were attributed to desorption of moisture from the cylinder walls as the cylinder pressure decreased.

To test the degree to which water vapor increases because of desorption from the cylinder wall, cylinders were immersed in a $55{ }^{\circ} \mathrm{C}$ water bath for 30 minutes. The water vapor concentration increased from 62 to $115 \mathrm{ppm}$ following cylinder heating, while the NDIR (non-dispersive infrared) analysis signal for $\mathrm{SO}_{2}$ was unchanged. The use of a drying trap prior to the moisture analyzer decreased the trace water vapor content, but did not affect the NDIR measurement of $\mathrm{SO}_{2}$. Measurement of water vapor as a function of time after cylinder heating showed that cylinder surface absorption of water vapor re-occurred (Figure 8 ). Packing a cylinder in ice resulted in a decrease in water vapor concentration due to increased cylinder surface absorption. The ice-packed cylinder decreased in water vapor concentration from 85 to $61 \mathrm{ppm}$, and increased to $67 \mathrm{ppm} 3.5$ hours after removal from the ice bath.

From these studies, it was confirmed that: (1) water vapor content is generally greater in batch cylinders which have diminished $\mathrm{SO}_{2}$ levels relative to the batch standard, indicating a possible effect of trace water level on $\mathrm{SO}_{2}$ 1oss; (2) water vapor increases as cylinder pressure is decreased (or as cylinder temperature is increased), due to desorption of water from the cylinder wall surface; and (3), that an increase in water vapor does not evidence any immediate effect on the lowering of the observed $\mathrm{SO}_{2}$ concentration in the cylinder. Further experiments are necessary to determine whether an increase in the concentration of water vapor will have long term effects on $\mathrm{SO}_{2}$ concentration, and hence, on $\mathrm{SO}_{2}$ concentration stability. 


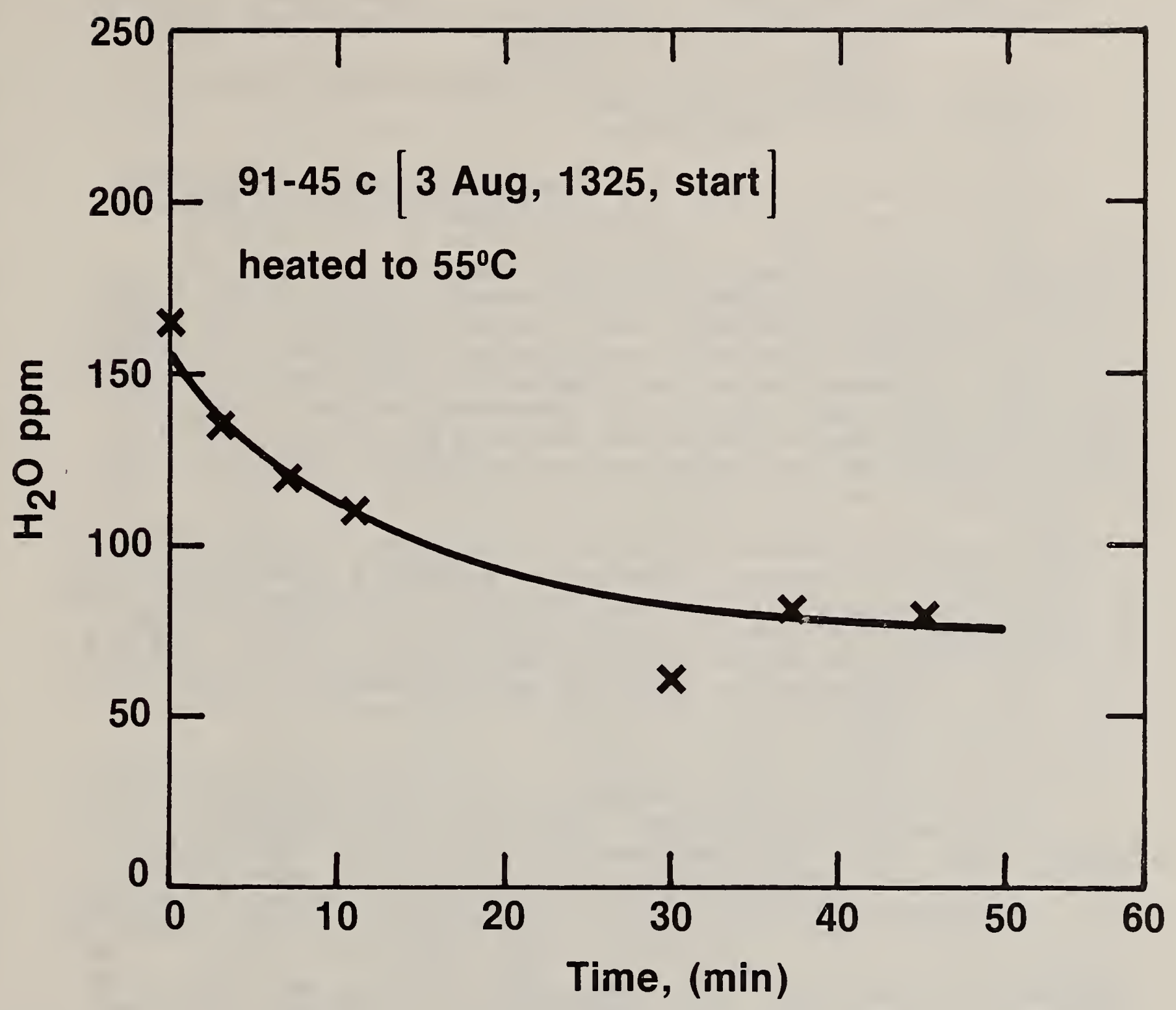

Figure 8. Decreases in cylinder water vapor (ppm) due to surface resorption as a function of time (minutes) after cylinder heating to $55^{\circ} \mathrm{C}$. 
C. R. Hubbard and A. L. Dragoo

Materials Chemistry Division

Center for Materials Science

Characterization of the mean crystallite size in the range 100 to $1000 \AA$ can be done rapidly and nondestructively by $x-r a y$ powder diffraction (XRD). Crystallite size is difficult to measure by SEM due to agglomeration. Knowledge of the crystallite size is important in understanding sintering of some speciality ceramics. Crystallite size is often useful in rapidly assessing the reactivity of a heterogeneous catalyst. To date, no calibration standards are available for instrument calibration or procedure testing. Because of dependence on instrumental effects and the complexity of the analysis procedure, results from different laboratories are not comparable. Development of an XRD Crystallite Size SRM will alleviate this problem.

Mg0 has been chosen as a crystallite size standard, with two or three SRM's to be prepared with sizes ranging from 100 to $1000 \AA$. Microcrystals with excellent habit are being formed from an MgO smoke and collected with an electrostatic precipitator. The size of these microcrystals will be measured with an SEM and then used to calibrate the diffraction measurements. Bulk quantities of MgO are being prepared by calcination of basic magnesium carbonate.

The stability to the atmosphere $\left(\mathrm{H}_{2} \mathrm{O}, \mathrm{CO}_{2}\right.$, etc. $)$ has been checked by two different tests. In the first, a sample was mounted for diffraction measurements, left in the laboratory air, and XRD data collected six times over a period of nearly 700 hours. The mean crystallite size in the (200) direction remained essentially constant, while in the (111) direction, the mean size dropped in the first few hours and then stabilized. The integrated intensity of the (200), (400), (111), and (222) lines followed this same rapid drop and then stabilization. A second sample mount was exposed to a high humidity environment (saturated air at $60{ }^{\circ} \mathrm{C}$ ). Again, the (111) direction showed a quick drop in mean crystallite size, while the mean size in the (200) direction was stable. Integrated intensities also showed an initial decrease and then constant value. No second phase diffraction (e.g., MgOH) lines have been found in either mount.

Changing the calcination temperature is expected to increase the mean crystallite size. Two methods of measuring the mean crystallite size were employed to evaluate the effects of calcination temperature on the mean crystallite size. Using the Warren-Averbach method, we obtained a change in crystallite size in the (200) direction from 116 to $246 \mathrm{~A}$, corresponding to 600 and $900{ }^{\circ} \mathrm{C}$. Using the Stokes integral breadth method, a somewhat larger crystallite size was determined for the samples prepared 
at higher temperature. This likely indicates an increase in strain in the crystallites prepared at higher temperature.

.15 Chemical Speciation/Biodeterioration of SRM's

G. J. Olson, W. P. Iverson, and F. E. Brinckman

Materials Chemistry Division

Center for Materials Science

With OSRM support we developed and applied metal speciation techniques to analyze several SRM's (shale oil, freeze-dried urine, oyster tissue, bovine liver) for levels of certain metal species, with the goal of providing OSRM with molecular composition of an SRM in terms of selected elements. Increased requests for information on our work from Government, industrial, and academic scientists around the world reflect growing recognition of the importance of, and prospects for, determining trace metal-containing molecular entities in biological materials. Our work includes the first metal speciation study of a clinical standard, and will greatly assist OSRM in meeting growing needs for related new biological standards. We have also examined several new SRM's (freeze-dried urine, bovine liver, citrus leaves) for sterility and developed a new biodeterioration screening technique for OSRM which allows a rapid diagnosis in cases where an SRM is suspected to be contaminated.

In last year's report we described development and preliminary applications of a new ultratrace analytical method employing a tin-specific flame photometric detector (FPD) automatically coupled to a purge and trap gas chromatograph $(P / T-G C)$. We have concluded an evaluation of this technique for speciation and quantitation of a heavy metal in a clinical SRM being re-released by the NBS Office of Standard Reference Materials as (new) Freeze-Dried Urine.

In the urine SRM's, volatile sulfur compounds are detected in both S- and Sn-electrive modes; involatile ionic tin compounds require borohydride reduction for their volatilization as stannanes into the GC system and are detected only in the $S n$ mode. Some of the major species identified include $\left(\mathrm{CH}_{3}\right)_{2} \mathrm{SnH}_{2}$ and $\left(\mathrm{CH}_{3}\right)_{2} \mathrm{~S}_{2}$. A monobutyltin species, $\mathrm{C}_{4} \mathrm{HgSn}^{3+}$, (determined as $\mathrm{C}_{4} \mathrm{H}_{9} \mathrm{SnH}_{3}$ ) appears in the same chromatogram. Quantitative results are summarized in Table 7.

There are both qualitative and quantitative differences between the two SRM's, doubtless reflecting different polled sources. Detection of a butyltin species in both materials is a notable finding since there are no known biological butylation reactions comparable to biomethylation. These results may indicate human exposure to increased worldwide industrial use of butyltins, at least in the SRM source population. As a wide spectrum of organotins find greater use in manufacturing and biocides, methods and standards for health monitoring and 
Table 7. Concentrations ${ }^{\mathrm{a}}$ of Tin and Sulfur Species in Previous and New NBS Freeze-Dried Urine SRM's

\begin{tabular}{lcl}
\hline \multicolumn{1}{c}{ Species } & "0ld" SRM & "New" SRM \\
\hline$\left(\mathrm{CH}_{3}\right) \mathrm{Sn}^{3+}$ & 1.0 & ND \\
$\left(\mathrm{CH}_{3}\right)_{2} \mathrm{Sn}^{2+}$ & $\mathrm{ND}$ & 0.46 \\
$\mathrm{C}_{4} \mathrm{H}_{9} \mathrm{Sn}^{3+}$ & 1.5 & 0.03 \\
Inorganic Sn(II) or Sn(IV) & 28.1 & ND \\
$\left(\mathrm{CH}_{3}\right)_{2} \mathrm{~S}_{2}$ & ND & 2.73 \\
\hline
\end{tabular}

a By method of additions: in $\mu \mathrm{g} / \mathrm{L}$; ND $=$ not detected.

NBS SHALE OIL SAM 1580

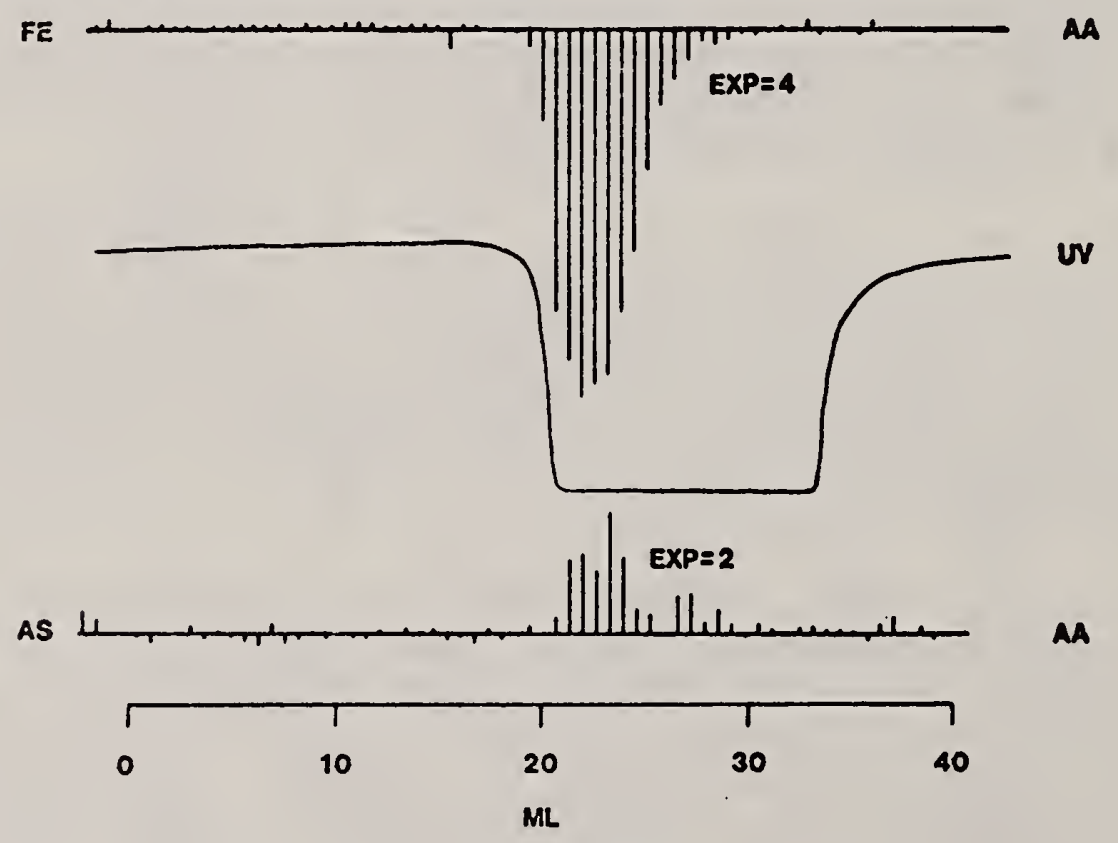

Figure 9. Dual-element SEC-GFAA chromatograms specific for As and Fe are compared for the NBS Shale 0il SRM in tetrahydrofuran. The maximum absorptivity in the tandem UV trace indicates the heavy organic loading of the oil. Co-elution of As with $\mathrm{Fe}$ at $22 \mathrm{~mL}$ suggests common macromolecular carriers with molecular weights of ca. 2500. Post-column addition of Ni(II) enhanced the As signal and insured equivalent As response throughout the elution. 
occupational exposure are needed. The SRM speciation methods now demonstrated can greatly assist in meeting these measurement requirements.

Another important measurement development for standards involves our continuing use of HPLC coupled with graphite furnace atomic absorption spectrophotometric (GFAA) detectors for element speciation. During the past year, we devised means to improve sensitivity with automated post-column derivatization for HPLC-GFAA, so that little or no modification of the established chromatographic separations would be required. Part of our goal was achieved with a new mixing device that simultaneously receives regulated flows of HFLC effluent and various dilute transition metal salt "enhancer" solutions prior to transport into the GFAA detector. Thereby, the active surface of the GFAA cuvette is continually refreshed with enhancer to yield more reproducible atomizations with sensitivity increases up to 50-fold. This improved GFAA method was used to characterize As in the shale oil SRM.

For molecular characterization of arsenic in shale oil by size exclusion chromatography (SEC), a huge excess of carbonaceous residue must be charred before GFAA atomization. At the required temperatures over $1000{ }^{\circ} \mathrm{C}$, many arsenic compounds or their decomposition products volatilize and would not be detected. In this case, addition of nickel(II) solutions to the SEC-HPLC system gave optimum signal enhancement for both small, volatile molecules such as dimethylarsenic acid and As-containing macromolecular components of shales. OSRM has supported our efforts to evaluate NBS SRM 1580 Shale $0 i 1$ as a suitable matrix for speciating arsenic. Arsenic concentration in this material (which has been certified only for selected organic compounds) has been determined by GFAA to be $2 \pm 0.03 \mathrm{ppm}$. Using SEC-GFAA procedures noted above, we have successfully determined As content of SRM 1580 as a function of molecular weight in the range from 100 to 20,000. The arsenic eluted at retention volumes corresponding to 1500 to 2000 Daltons as depicted in figure 9. By using gradient anion exchange GFAA chromatographic methods developed in our group, we have isolated both methyl and phenylarsenic acid in source Green River formation shale oil of the type used for SRM 1580. Their presence, now confirmed collaboratively with Dr. R. H. Fish of Lawrence Berkeley Laboratory by derivatization GC-MS, illustrates for the first time unequivocal independent evidence for true organometals in a major fossil fuel source matrix.

Installation of an epifluorescence microscope facility in the Group's laboratories enabled us to develop new, rapid methods to examine microbial attack on SRM's. The biodeterioration of SRM's, especially those based on naturally-occurring matrices for clinical and environmental users, was rapidly assessed using fluorescent dyes to detect microbial growth in contaminated liquid (urine) and solid (oyster tissue, orchard leaves) SRM's. Such methods can be used by OSRM and its customers to quickly 
examine SRM's suspected of being microbially contaminated without costly microbial culture media, sterilization and incubation

facilities.

.16 Research on Dye Penetrant Microhardness and Thickness SRM's

D. S. Lashmore

Materials Chemistry Division

Center for Materials Science

(1) Dye penetrant crack SRM's have been in production for two years and last year more than 100 were made. This SRM is fabricated using electro-forming technology and consists of alternative layers of copper and nickel. There are four layers of copper: the thickest is nominally $2 \mu \mathrm{m}$, then next $1 \mu \mathrm{m}$, followed by $0.5 \mu \mathrm{m}$ and $0.2 \mu \mathrm{m}$. These copper layers are then electrochemically removed and the space that the copper occupied constitutes the crack. A research project was undertaken to improve various unsatisfactory manufacturing techniques and to investigate several important aspects of the crack geometry that have a bearing on dye pick-up and apparent crack width. Among the topics that were examined were (a) the extent to which the crack edge was "rounded" and by the etching procedure; (b) the depth to which the crack penetrated into the block; (c) the polishing technique which was known to "smear" the nickel over the copper; and (d) various techniques to automate the production process. In order to eliminate as much as possible the rounding of the crack, an improved etching technique was developed and the polishing procedure was change to reduce to the maximum extent possible the smearing of the nickel. The depth of the crack was also measured. This project is quite important as the Federal Aviation Agency is mandating the use of our dye penetrant crack blocks for use in the inspection of commercial aviation (wing spars, landing gears, etc.). We anticipate producing from 300 to 500 of these standards next year.

(2) In response to a request from the offices of Standard Reference Materials and Nondestructive Evaluation, we have developed two new microhardness Standard Reference Materials, one of $100 \mathrm{~kg} / \mathrm{mm}^{2}$ and another about $500 \mathrm{~kg} / \mathrm{mm}^{2}$. The main problems with the standards now available from the makers of the microhardness instruments are typically (a) the lack of uniformity of hardness across the surface, and (b) the lack of a certified hardness. The hardness non-uniformity is a result of inhomogeneities in cooling rate and the resultant composition, inhomogeneity, and grain size variation. Electrodeposition technology allows almost an atomic control of structure and composition. We have succeeded in fabricating hardness SRM's of significantly improved hardness uniformity. These will be made available through the Office of Standard Reference Materials some time next year. Research in this area is continuing to extend the range of hardness to over $1000 \mathrm{~kg} / \mathrm{mm}^{2}$ so that a complete set of standards will be available. We have had a number of requests 
from industry for Rockwell hardness standards which we will be evaluating next year.

(3) Improved software involving a more accurate nonlinear least squares fitting procedure was implemented as were improved operating procedures for the $x$-ray fluorescence apparatus itself. Using these new improvements in our measurement technology, we have been able to fabricate a number of very thin, gold SRM's $(0.13 \mu \mathrm{m}$ and $0.25 \mu \mathrm{m})$ which will be made available to the public through OSRM.

Improved plating procedures for the gold deposition now allows all plating to be done "in-house" resulting in improved coating quality and rapid response to requests for new SRM's.

The $x-r a y$ fluorescence apparatus has been directly connected to our S-100 computer to enable almost real-time data reduction. This procedure eliminates the old teletypewriter which was used to store the data on punched tape and then used to read the tape over a phone modem to a large mainframe computer which eventually returned the reduced data to the teletype. The old system was not only very costly but more importantly was quite unreliable.

\section{.17 Glass Standard Reference Materials}

M. Cellarosi

Materials Chemistry Division

Center for Materials Science

\section{(1) Dielectric Constant SRM}

Certification of SRM 774 for Dielectric Constant and related Loss Characteristics was accomplished this year.

Development of this standard and improved methodology was carried out in collaboration with ASTM Committee C14 on Glass Properties and industrial laboratories, principally to resolve serious measurement errors that existed in industry. SRM 774 now on sale, will provide support to the expanding role of glass in electrical/electronic applications. The standard will also help in energy conservation efforts (e.g., low loss insulators and dielectrics), and in the evaluation of other materials properties such as dielectric breakdown, moisture content, deterioration, etc.

\section{(2) Glass High Temperature Resistivity SRM}

In cooperation with ASTM Committee C14 on Glass Properties and the glass industry work is in progress to develop this standard and related measurement methods. This project was undertaken in response to a priority listing generated by industry. 
Glass resistivities as a function of temperature in the molten range are important parameters for effective utilization of electric power, productivity, quality, and for reduction of air pollution from furnaces. Resistivity data is also important in the design of melt/process equipment. This SRM will benefit primarily the glass industry as melting operations are modernized and converted to electrical power.

NBS leads the ASTM task force to develop the SRM and standard methods. Procedures and samples (SRM 711, Viscosity Standard) have been distributed. Interlab comparisons now in progress utilize high temperature viscometry methods for the generation of simultaneous resistivity/viscosity data. Calibrations and study of techiques are in progress at NBS.

(3) Glass Viscosity SRM

A new improved high temperature viscometer is being constructed in anticipation of replacing viscosity SRM 710 (soda-lime-silica glass). This viscometer utilizes a commercially available torque measuring system and a furnace designed at NBS. Furnace construction and refinement of mechanical details are planned to allow ample time for calibration prior to SRM certification.

.18 Catalyst Package for Lubricant 0xidation Tests

C. S. $\mathrm{Ku}$

Materials Chemistry Division

Center for Materials Science

Lubricants in service encounter a chemically harsh environment. Combustion gases carrying partially oxidized fuel components have been identified as the key chemical species that control the degradation pathway of the lubricants. Realistic simulation of the engine environment requires the synthesis of the reactive species in the combustion gases.

A procedure to synthesize these species has been developed. This material when used in laboratory bench tests simulates the critical chemical reaction pathway which exists in an operating engine, and enables significant correlation to be obtained between bench tests and engine tests.

A high boiling fraction $\left(>150^{\circ} \mathrm{C}\right)$ of a gasoline is oxidized in the presence of $2000 \mathrm{ppm} n i t r o g e n$ dioxide at $125^{\circ} \mathrm{C}$ for 72 hours. The oxidation is terminated when the total acid number (TAN) of the oxidized/nitrated fuel components reaches about 15 . The fuel components are then neutralized with saturated sodium bicarbonate solution to a TAN of about 2. The neutralized product is used as the oxidized/nitrated fuel fraction. 
The oxidized/nitrated fuel fraction can be used with a soluble metal naphthenate mixture ( $\mathrm{Pb} / \mathrm{Fe} / \mathrm{Cu} / \mathrm{Mn} / \mathrm{Sn}$ : $82 \% / 7 \% / 4 \% / 3.5 \% / 3.5 \%)$. These metals have been found in used oil analyses to test automotive engine lubricants. The NBS thin-film oxidation test uses five percent of each of the oxidized fuel fractions and metal mixtures in evaluating the oxidation stability of automotive crankcase lubricants. The test measures the oxidation induction times of the test lubricants. Test data on ASTM IIID engine test stand reference oils are compared with those with no fuel and metal catalysts in Table 8 . The data indicates that the use of the fuel components and metal catalysts significantly changes the relative oxidation stabilities of the reference oils. A batch apparatus has been set up for the fuel oxidation. This temperature controlled apparatus is a scaled up version of an earlier operation. A five liter three-neck glass flask is used as the reactor to replace test tube operation ( $100 \mathrm{~mL}$ ) previously used. Air is bubbled into the fuel fraction and is mixed up with the fuel by an air-driven stirrer to ensure uniform oxidation. The oxidation temperature is measured by thermal couplers connected to the temperature controller. If the temperature of the fuel fraction becomes higher than the predetermined safety set point, the controller will shut off the air supply and the power.

With this scaled up version of the fuel catalyst preparation, we are now in a position to produce sufficient quantities of the catalyst for SRM production.

\section{.19 Self-Calibrating Gel Permeation Chromatography}

I. C. Sanchez

Polymer Science and Standards Division Center for Materials Science

Gel permeating chromatography is a widely accepted technique for estimating the molecular weight distribution (MWD) of high polymers. However, the usefulness of the conventional GPC apparatus is limited by the need to provide calibrants for each polymer measured of known molecular weight over the entire molecular weight range in which the MWD is significantly different from zero. The calibration depends, among other things, upon the chemical nature, degree of branching, etc., of the polymeric material so that each new material requires a fresh calibration. The so-called "universal calibration" hypothesis, while useful, is limited to comparisons of polymers of similar shape and, in any event, is inadequate for quantitative determinations. Some instruments, one of which is commercially available, attempt to circumvent the need for calibrants by adding a single-angle light scattering detector to the usual concentration-sensitive detector. However, this does not allow the extrapolation to zero scattering angle which is required, in principle to relate scattering intensity to molecular weight. In 
Table 8. Comparison of Thin-Film Test Results With and Without Fuel Catalysts

Test Conditions: $1.5 \mathrm{~g} 0 \mathrm{il}$

$160{ }^{\circ} \mathrm{C}$

$2 \%$ water

$620 \mathrm{KPa}$ Initial Oxygen (90 psig)

\begin{tabular}{|c|c|c|c|c|}
\hline \multirow[t]{3}{*}{$0 i 1$} & \multirow[t]{3}{*}{ IIID Hours** } & \multirow[t]{3}{*}{$\begin{array}{l}\text { IIID Pass*** } \\
\text { or Fail } \\
\end{array}$} & \multicolumn{2}{|c|}{$\begin{array}{c}\text { Thin-Film Test } \\
\text { Induction Time (min) }\end{array}$} \\
\hline & & & Wi thout & With \\
\hline & & & $\mathrm{Cu} \& \mathrm{Fe}$ wires & 5 wt $\%$ Metal \\
\hline $76 \mathrm{~A}-1$ & 62 & Pass & $>590$ & 273 \\
\hline $75 B-1$ & 56 & $"$ & 395 & 193 \\
\hline $73 B-1 *$ & 48 & $"$ & --- & 116 \\
\hline $79 A$ & 40 & $"$ & 254 & 155 \\
\hline $81 \mathrm{~A}$ & 40 & $"$ & --- & 101 \\
\hline $77 \mathrm{~B}-1$ & 24 & Fail & 245 & 60 \\
\hline $77 \mathrm{C}$ & 16 & $"$ & 181 & 44 \\
\hline $72 A-1$ & 16 & $"$ & 181 & 39 \\
\hline
\end{tabular}

*High wear oil (fail wear criterion).

**Hours for $375 \%$ viscosity increase in sequence IIID engine test.

***An oil is a pass oil if its IIID engine test viscosity increase at $40 \mathrm{hr}$. is less than 375\%; otherwise the oil is a fail oil.

Note: Test repeatability is $\pm 5 \%$. 
addition, qualitative information on the variation of scattering with angle, normally required to give assurance that meaningful results are being obtained, is not available.

We are designing and constructing a light scattering detector for the GPC which measures; in real time, the scattering intensity as a function of scattering angle and which is controlled by a dedicated minicomputer in a way that allows scattering to be measured as a function of scattering angle and concentration. The instrument will allow continuous monitoring of the variation of scattering with angle. This will allow immediate identification of difficulties such as association, microgel formation, etc., which could affect the validity of the molecular weight obtained, an important consideration for work on new and unstudied materials. In addition to molecular weight, the mean-square radius (radius of gyration) will be obtained as a function of molecular weight, at least in the higher ranges of molecular weight, providing useful information for the characterization of branched polymers.

In FY83 we will start making measurements with the completed instrument and developing procedures for high-quality molecular weight determinations.

\section{.20 Metallurgical Research}

A. W. Ruff

Metallurgy Division

Center for Materials Science

Five projects are underway involving Standard Reference Materials. One project involves the development and certification of a Standard Reference Material (SRM) for use with the new Dry Sand/Rubber Wheel Abrasion Test (ASTM Standard á65-80). Approximately 250 specimens of D-2 tool steel, the material which was selected for this application, have been prepared. Certification tests using NBS equipment have been completed and the statistical analysis and writing of the certification statement are expected to be completed in FY83. An additional 750 SRM specimens are being prepared for later issue. Publication of ASTM G65-80, "Standard Practice for Conducting Dry Sand/Rubber Wheel Abrasion Tests" has evoked considerable interest among producers of abrasive wear resistant materials, manufacturers of equipment subject to abrasive wear, and users of these materials and equipment. The Dry Sand/Rubber Wheel wear test is especially applicable for ranking materials exposed to conditions involving so-called three-body abrasion as might be encountered in earth moving and agricultural equipment, in mining, and certain ore processing machinery. A workshop sponsored by ASTM Committee G-2 on Erosion and Wear was held in June for the specific purpose of addressing problems which might be encountered in applying this Dry Sand/Rubber wheel test, and to consider the influence that changes in various test conditions 
and parameters might have on test results. The importance of a suitable calibration specimen was clearly recognized during the course of this workshop. We contributed one paper to the workshop illustrating the effect of sand flow rate and moisture content on the wear rate using this test.

Another project is investigating the feasibility of using new metal processing techniques such as electron-beam (EB) surface melting and fiber melt spinning to produce microhardness standards. This work was supported by the office of Standard Reference Materials and was conducted in conjunction with the NBS Electrodeposition Group (D. Lashmore, Materials Chemistry Division). Electron-beam surface melting techniques developed in the Metallurgy Division processing laboratory were used on $440 \mathrm{C}$ stainless steel bar stock to see whether areas of sufficient homogeneity of microhardness suitable for low load microindentation testing (0.098-0.98N loads) could be produced. Although the EB zones in the stainless steel were quite microstructurally uniform, electroformed Cu-based materials with a similar microhardness range showed much better reproducibility of microhardness numbers. The decision was made to produce electroformed Cu standards for this reason. Work continues on characterizing melt-spun ribbons of Pd80Ge20 for possible use as staridards in other microhardness number ranges. Additionai work on characterizing heat-treated, electroformed co-based materials for standards is planned for the coming year, also in conjunction with the Materials Chemistry Division.

One project supported by the Office of Standard Reference Materials concerns the development of standards for use with the ferrographic method of analysis of wear debris particles in lubricants. This method has proven itself as a viable condition monitoring tool; however, the quantitative capability involved needs improvement. After participating in several interlaboratory measurement rounds, it became clear that certain problems of precision and bias could be overcome if adequate standards were available. Development of an artificial sample of wear is now in progress, and should help to further quantify the overall method.

Quantitative image analysis was employed in a project completed this year to aid in the development of standardized methods for characterizing the geometric shapes of sand particles for use in dry sand/rubber wheel (DSRW) tests. A perimeter ratio $(P R)$ parameter was used to evaluate the variations in abrasive sand particle shapes in batches of sand used in testing over a several year period. These ratio parameters remained very constant from batch to batch in the rounded AFS 50-70 sand specified for the ASTM DSRW procedure. Sharper particles produced by crushing quartz and screening it to the same sieve size range as the AFS 50-70 sand had larger PR parameters to start with and produced greater amounts of abrasive wear on steel samples. Image analysis comparing both used and unused sand showed that the average PR parameters for AFS 50-70 and for 
crushed quartz remained relatively constant before and after the abrasion tests. However, there appeared to be increases in the standard deviations of PR parameters of both kinds of abrasives after use in DSRW tests. Further work is planned using a new image analysis system to investigate larger sample sizes and to more completely automate the shape classification procedure. This future work should improve the statistical significance of $P R$ data by shortening the time required to analyze larger numbers of particles.

Another project is concerned with the need to develop performance standards for medical and surgical devices. The test methods developed in ASTM, for example, for materials can be used for this purpose. This past year, the ASTM F746-82 "Standard Method of Test for Pitting or Crevice Corrosion of Metallic Surgical Implant Materials" was passed. NBS participated for many years with other university and industrial laboratories in developing this test and conducting interlaboratory tests. This is the first standard corrosion test for surgical implant metals, and it will be followed by the production of the NBS $316 \mathrm{~L}$ stainless steel Standard Reference Material (SRM) for use with the standard test. NBS has obtained $316 \mathrm{~L}$ stainless steel for use as Standard Reference Material from the supplier who furnished the round-robin specimens and who supplies implant manufacturers. Work on the SRM production is underway and some studies to refine the test are being conducted in terms of effects of solution oxygen content, solution $\mathrm{pH}$ and metal surface condition.

.21 Computer Magnetic Media

$$
\text { S. B. Geller }
$$

System Components Division

Institute for Computer Sciences and Technology

\section{(1) Minicassette Magnetic Tape SRM's}

Four Raymond Mini-Raycorder Model 6409 minicassette drives, and 50 minicassettes were obtained. A field control unit was designed in order to control the forward and reverse motion of the media as well as the on-off read/write control functions. Some logical card functions were redesigned in order to allow for both frequency and automatic current level controls. Initial signal amplitude tests were performed through the use of the NBS reference measurement system. The results of these tests, although preliminary, indicated that these very inexpensive Model 6409 drives do not appear to have the speed stability which will be required from SRM reference machines. At the present time, it is uncertain whether it will be cost effective to finance the design of a precision minicassette reference drive if one is not available commercially. 


\section{(2) Very High Density Magnetic Tape Cartridge SRM's}

No commercial announcements were made until late FY82 relative to the release of new high density products. Maintained contact with technical personnel directly engaged in the development of these products and was advised that products will be available during FY83. This high density program will receive a high priority in FY83.

(3) Care and Handling of Computer Magnetic Media Special Publication

The following sections are at least 90 percent completed:

1. Environmental recommendations and remarks.

2. Clean operations recommendations and remarks.

3. Technical handling recommendations and remarks.

4. Causes for data losses on computer storage media.

5. Scheduled tape maintenance.

6. Description of equipments for cleaning, certifying, and evaluating tapes.

7. Tape rehabilitation processes.

8. Clean room theory and types of rooms.

9. Guidelines for operations in clean room of all classes.

10. Effects of various external fields on data stored on magnetic tapes.

11. Effects of temperature, humidity, and winding methods on magnetic tapes.

12. The care and handling of computer tapes in long-term archival storage.

a) Results obtained from large tape populations.

b) Results derived from an experimental and theoretical study based on small sample statistics.

c) Recommended care and handling methods based on a) and $b$ ).

.22 Absolute Layer Thickness Measurements for Semiconductor Materials

D. Nyyssonen

Semiconductor Materials and Processing Division Center for Electronics and Electrical Engineering

The initial efforts on this project, begun in FY81, were directed toward 1) the design and fabrication of test patterns suitable for both the controlled characterization of the thickness and step-height of dielectric layers fabricated on silicon substrates and 2) the critical evaluation of available measurement techniques, including stylus profilometry, interferometry, and ellipsometry. In FY81, the test pattern 
4. OSRM STAFF PUBLICATIONS, INFORMATION TRANSFER AND COMMITTEE ACT IVITIES

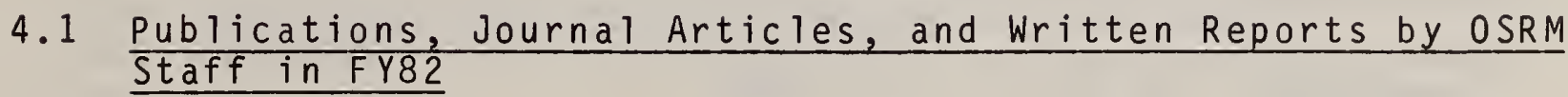

--Alvarez, R., "National Bureau of Standrds Standard Reference Materials Certified for Arsenic," sent 11-25-81 to be published in Proceedings of Arsenic Symposium Sponsored by Chemical Manufacturers Association and NBS. Held at NBS Nov. 4-6, 1981.

--Alvarez, R., "Report on Reference Materials and Standard Solutions," J. Assoc. Off. Anal. Chem., 65, 297 (March 1982).

--Alvarez, R., Rasberry, S. D. and Uriano, G. A., "NBS Standard Reference Materials: Update 1982," Anal. Chem. (to be published 0ct. 1982).

--Alvarez, R., "Citrus Leaves (SRM 1572); a New NBS Plant Tissue SRM Certified for trace Element Concentration, " Proceedings of the Ninth International Plant Nutrition Colloquium, available Commonwealth Agricultural Bureaux, Farnham House, Farnham Royal, Slough SL2 3BN, U.K.

--Garner, E. L., Gills, T. E. and Moore, L., "Current Status of NBS Isotopic Standards and Future Role of SRM's for Nuclear Energy," Proceedings of the 30 th Annual Conference of the American Society for Mass Spectrometry and Allied Topics, Honolulu, Hawaii, June 1982 .

--Kirby, R. K., "Recent Activities of the National Bureau of Standards and the American Society for Testing and Materials in Developing Particulate Standard Reference Materials," Proceedings of the Third Symposium on Advances in Particle Sampling and Measurement, Daytona Beach, Florida, October 21,1981 .

--Rasberry, S. D., ed., "Reference Materials," American Laboratory, 13 (10) pp. 159-160 (1981).

--Rasberry, S. D., ed., "Reference Materials," American Laboratory, 13 (11) pp. 156-157 (1981).

--Rasberry, S. D., ed., "Reference Materials," American Laboratory, 13 (12) p. 84 (1981).

--Rasberry, S. D., ed., "Reference Materials," American Laboratory, 14 (1) pp. 112-115 (1982).

--Rasberry, S. D., ed., "Reference Materials," American Laboratory, 14 (2) pp. 182-186 (1982). 
--Rasberry, S. D., ed., "Reference Materials," American Laboratory, 14 (3) p. 178 (1982).

--Rasberry, S. D., ed., "Reference Materials," American Laboratory, 14 (4) p. 114 (1982).

--Rasberry, S. D., ed., "Reference Materials," American Laboratory, 14 (5) p. 142 (1982).

--Rasberry, S. D., ed., "Reference Materials, "American Laboratory, 14 (7) p. 80 (1982).

--Rasberry, S. D., ed., "Reference Materials," American Laboratory, 14 (8) pp. $76-77$ (1982).

--Rasberry, S. D., ed., "Reference Materials," American Laboratory, 14 (9) pp. 140-141 (1982).

- Uriano, G. A. and Rasberry, S. D., eds., "Annual Report 1982 Office of Standard Reference Materials (1982).

4.2 Technical Lectures/Talks Given by OSRM Personnel

--Alvarez, R., "What Committee E-2 Should Know About Non-Metal SRM's," ASTM Committee E-2 on Emission Spectroscopy Symposium held at the National Bureau of Standards, Oct. 1, 1981.

- -Alvarez, R., "Role of National Bureau of Standards Standard Reference Materials in Quality Assurance Programs for Health-Related Analyses," 95 th Annual Meeting, Association of Official Analytical Chemists, Marriott Twin Bridges, Washington, D.C., Oct. 20, 1981 .

- Alvarez, R., General Referee's Report on Reference Materials and Standard Solutions, 95 th Annual Meeting. Association of Official Analytical Chemists, Marriott Twin Bridges, Washington, D.C., Oct. 20, 1981 .

--Alvarez, R., "National Bureau of Standards Standard Reference Materials Certified for Arsenic, "Arsenic Symposium (Session II), sponsored by the Chemical Manufacturers Association and NBS, Office of Environmental Measurements, held at NBS, Gaithersburg, MD, Nov. 4, 1981.

--Alvarez, R., "New developments in Standard Reference Materials, "Chemical Society of Washington, Catholic University, Washington, D.C., Nov. 12, 1981.

--Alvarez, R., "New Clinical, Environmental, and Other HealthRelated National Bureau of Standards Standard Reference Materials and Their Application in Laboratory Quality Control," 
Department of Health Services, Berkeley, CA, March 26, 1982.

--Alvarez, R., "National Bureau of Standards Standard Reference Materials Certified for Constituents of Environmental Importance, "American Chemical Society, Las Vegas, NV March 29, 1982 .

--Alvarez, R., "New Developments in Clinical and Other Health Related Standard Reference Materials for Quality Assurance Applications," Las Vegas, Nevada, March 31, 1982.

--Alvarez, R., "New National Bureau of Standards Environmental Standard Reference Materials Certified for Priority Pollutants," Las Vegas, Nevada, March 31, 1982.

--Alvarez, R., "NBS Standard Reference Materials--Their Use in Determining and Maintaining Measurement Accuracy, "Maryland Junior Academy of Sciences, Maryland Science Center, Baltimore, MD, April 17, 1982.

--Alvarez, R., "Recent Developments in NBS Standard Reference Materials and Their Role in Laboratory Quality Control," Society for Applied Spectroscopy - Florida Section, University of Florida, Gainesville, FL, April 19, 1982.

--Alvarez, R., "Recent Developments in NBS Standard Reference Materials and Their Role in Laboratory Quality Control," Society for Applied Spectroscopy - Houston Section, Houston, TX, April 20, 1982.

--Alvarez, R., (same title as 4-20-82), Society for Applied Spectroscopy - Indiana Section, Indianapolis, IN, April 21, 1982 .

--Alvarez, R., (same title as 4-20-82), 4th Midwest Analytical Chemistry Symposium, Columbia, Mo, April 22, 1982.

- -Alvarez, R., "Recent Developments in National Bureau of Standards Standard Reference Materials and Their Role in Laboratory Quality Control, " 4th Midwest Analyltical Chemistry Symposium, Columbia, MO, April 22, 1982.

--Alvarez, R., "Standard Reference Materials" (in Spanish), The American Institute of Foreign Study (Visitors from Spain), NBS, Gaithersburg, MD, July 12, 1982.

--Alvarez, R., "The Catalytic Concentration of Seven Enzymes in Lyophilized Human Serum, NBS SRM 909," - Co-author, American 34 th National Meeting, American Association for Clinical Chemistry, Anaheim, CA, Aug. 13, 1982.

--Alvarez, R., "Citrus Leaves (SRM 1572) - A New NBS Plant Tissue 
Standard Reference Material Certified for Trace Element Concentrations, "Ninth International Plant Nutrition Colloquium, Coventry, U.K., Aug. 24, 1982.

--Alvarez, R., "New Development in NBS Environmental Standard Reference Materials," VIII Annual Meeting of the Federation of Analytical Chemistry and Spectroscopy Societies, Philadelphia, PA, Sept. 22, 1982 .

--Alvarez, R., "New National Bureau of Standards Food and Plant Tissue Standard Reference Materials Certified for Trace Element Concentrations," VIII Annual Meeting of the Federation of Analytical Chemistry and Spectroscopy Societies, Philadelphia, PA, September 23, 1982.

--Gills, T. E., (invited talk) "The Role of NBS Standard

Reference Materials in Measurement Systems for Environmental Analysis and Monitoring, "Pittsburgh Conference and Exposition, Atlantic City, NJ, March 1982

--Gills, T. E., (invited talk) "SRM's in Environmental Measurement," Department of Chemistry, University of Maryland, College Park, MD, April 1982.

--Kirby, R. K., "Standard Reference Materials," ASTM Committee E-37, Philadelphia, PA, April 5, 1982.

--Kirby, R. K. and Alvarez, R., "Standard Reference Materials for Quality Assurance of Clinical Measurements, "34th National Meeting of the American Association for Clinical Chemistry, Anaheim, CA, Aug. 12, 1982 .

--Rasberry, S. D., "The Role of SRM's in Quality Assurance Center for Professional Advancement Course on Qualilty Assurance, East Brunswick, NJ, Jan. 26, 1982.

--Rasberry, S. D., "The Role of SRM's in Quality Assurance," NBS Course on Quality Assurance, Gaithersburg, MD, May $27,1982$.

--Reed, W. P., "Preparation and Certification of Standard Reference Materials," Seminar sponsored by NBS Center for Analytical Chemistry, Inorganic Analytical Research Division, Gaithersburg, MD, April 15, 1982.

--Uriano, G. A., "Overview of the NBS Standard Reference Materials Program," Presentation to Deputy Secretary of Commerce, Guy Fiske, NBS, Gaithersburg, MD, March 17, 1982.

--Uriano, G. A., "The NBS Office of Standard Reference Materials," Directors of Industrial Research Analytical Group Meeting, NBS, Gaithersburg, MD, May 7, 1982. 
--Uriano, G. A., "The Development of a Trace Elements in Human Serum Standard Reference Material, "Interagency Working Group on Blood Resources and Blood Substitutes, National Institutes of Health, Rockville, MD, June 1, 1982.

\subsection{Standards Committee and Other Standards Activities}

Alvarez, R. - American Society for Testing and Materials (ASTM) Subcommittee on Reference Materials and Solutions

General Referee for Reference Materials American Society for Testing \& Materials (ASTM)

E-02 - Emission Spectroscopy

E-02.05 - Copper, Nickel, and High

Temperature Alloys

Gills, T. E. - American Society for Testing and Materials (ASTM)

C-26 on Nuclear Fuel Cycle

C -26.05 Test Methods

Kirby, R. K. - American Society for Testing and Materials (ASTM)

E-29 on Particle Size Measurement

E-37 on Thermal Measurement

E-37.02 on Standard Reference Materials

E-37.05 on Thermal Properties

S-21 Coordinating Committee for Standard

Reference Materials for Particle

Metrology

C-14 on Glass and Glass Products

C-14.91 on Standard Reference Materials

Rasberry, S. D. - American Society for Testing and Materials ( ASTM)

E-02 on Emission Spectroscopy

C-14.91 on SRM's for the Glass Industry

U.S. Pharmacopeia (Delegate)

Agency for International Development (Standards

Assistance to Egypt)

Reed, W. P. - American Society for Testing and Materials (ASTM)

E-2 on Emission Spectroscopy

E-3 on Chemical Analysis of Metals

C-26 on Nuclear Fuel Cycle

C-26.07 on Waste Materials (Chairman)

S-17 ASTM-NBS Research Associate Program American National Standards Institute

N15 Nuclear Standards

Seward, R. W. - American Society for Testing and Materials (ASTM) E-13 on Molecular Spectroscopy

E-13.01 on UV and Visible Spectroscopy 
Uriano, G. A. - American Society for Testing and Materials (ASTM)

E-02 on Emission Spectroscopy

U.S. Delegate to ISO Council Committee on

Reference Materials (REMCO)

Chairman of ISO/REMCO

Consultant to Standards Committee, American

Association for Clinical Chemistry

Vice Chairman, Secretary and Titular Member of

Commission I.4 on Physico-chemical Reference

Materials and Standards, International Union of

Pure and Applied Chemistry

Consultants' Panel on Analytical Quality Control,

International Atomic Energy Agency, United Nations

Consultants' Panel on Coal Reference Materials,

Basic Energy Sciences Division, U.S. Department of Energy

\subsection{NBS Special Publication 260 Series}

The OSRM is responsible for the publication and dissemination of information on all phases of the preparation, measurement, certification, and utilization of SRM's. One of the major mechanisms for carrying out this responsibility is the publication and distribution of the NBS Special Publication 260 Series on SRM's. Since 1964 over 70 SP 260 reports--authored primarily by technical division staff--have been published, describing the preparation and use of a variety of SRM's and associated measurement methods. In FY82, the following SP $260^{\prime} s$ were published by OSRM:

- Marinenko, R. B., Standard Reference Materials: Preparation and Characterization of $K-411$ and $K-414$ Mineral Glasses for Microanalysis: SRM 470, NBS Spec. Publ.260-74 (April 1982) $\$ 3.50$.

--Weidner, V.R., Hsia, J. J., Standard Reference Materials: Preparation and Calibration of First Surface Aluminum Mirror Specular Reflectance Standards (SRM 2003a), NBS Spec. Publ. $260-75$ (May 1982) \$3.75.

--Hicho, G. E. and Eaton, E. E., Standard Reference Materials: A Standard Reference Material Containing Nominally Five Percent Austenite (SRM 485a), NBS Spec. Publ. 260-76 (August 1982) $\$ 3.50$.

--Furukawa, G. T., Riddle, J. L., Bigge, W. G., and Pfieffer, E. R., Standard Reference Materials: Application of Some Metal SRM's as Thermometric Fixed Points, NBS Spec. Publ. 260-77 (August 1982) \$6.00.

--Hicho, G. E. and Eaton, E. E., Standard Reference Materials: 
Standard Reference Material Containing Nominally Thirty Percent Austenite (SRM 487), NBS Spec. Pub 1. $260-78$ (Sept. 1982) \$3.75.

NOTE: To order these publications, send order with remittance (add 25 percent for other than U.S. mailing) to Superintendent of Documents, U.S. Government Printing Office, Washington, DC 20402.

For further information, contact the office of Standard Reference Materials, Room B-311, Chemistry Building, National Bureau of Standards, Washington, DC 20234. Telephone: (301) $921-2045$.

\subsection{FY82 Technical Exhibits With Staffed SRM Displays}

-- Pittsburgh Conference on Analytical Chemistry and Applied Spectroscopy, Atlantic City, NJ, March 7-12, 1982 .

-- American Chemical Society Meeting, Las Vegas, NV, March 25-April 2, 1982.

- Society of Nuclear Medicine, Miami, FL, June 14-18, 1982 .

-- Air Pollution Control Association Meeting, New Orleans, LA, June 21-25, 1982 .

-- Nuclear Materials Management, Washington, $D C$, July $19-21,1982$.

-- American Association for Clinical Chemistry Annual Meeting, Anaheim, CA, August 9-13, 1982.

-- Federation of Analytical Chemistry and Applied Spectroscopy Societies, Philadelphia, PA, September 19-24, 1982 .

-- Labcon, Chicago, IL, September 28-30, 1982. 


1. PUBLICATION OR
REPORT NO.
NBSIR $83-2649$

BIBLICGRAPHIC DATA

SHEET (See instructions)

4. TITLE AND SUBTITLE

1982 Annual Report

office of Standard

Reference Materials

5. AUTHOR(S)

G. A. Uriano and S. D. Rasberry, Editors

6. PERFORMING ORGANIZATION (If joint or other than NBS. see insiructions)

7. Contract/Grant No.

NATIONAL BUREAU OF STANDARDS

DEPARTMENT OF COMMERCE

WASHINGTON, D.C. 20234

8. Type of Report \& Period Covered

9. SPONSORING ORGANIZATION NAME AND COMPLETE ADDRESS (Street, City. State, ZIP)

10. SUPPLEMENTARY NOTES

Document describes a computer program; SF-185, FIPS Software Summary, is attached.

11. ABSTRACT (A 200-word or less factual summary of most significant information. If document includes a s/gniflcant bibliography or literature survey. mention it here)

This report summarizes the technical activities of the Standard Reference Materials (SRM) program of the National Bureau of Standards. Status reports for SRM research and production projects are included in the areas of electrical properties, thermal properties, radioactivity, chemical composition, chemical stability, mechanical properties and optical properties. Projects covered are carried out by technical centers in the National Measurement Laboratory, National Engineering Laboratory, and the Institute for Computer Sciences and Technology. Also covered are a number of cooperative projects with other laboratories and SRM activities of a number of industrial research associates.

12. KEY WORDS (Six to twelve entries; alphabetical order; capitalize only proper names; and separate key words by semicolons) Analytical Chemistry; compositional analysis; physico-chemical properties; quality assurance; reference methods; Standard Reference Materials

13. AVAILABILITY

[] Unlimited

X] For Official Distribution. Do Not Release to NTIS

$\square$ Order From Superintendent of Documents, U.S. Government Printing Office, Washington, D.C. 20402.

14. NO. OF PRINTED PAGES

[ Order From National Technical Information Service (NTIS), Springfield, VA. 22/6I
15. Price 

